Subscriber access provided by Gothenburg University Library

\title{
Article
}

\section{Composites of Biopolymers and ZnO NPs for Controlled Release of Zinc in Agricultural Soils and Timed Delivery for Maize}

\author{
Natercia C. T. Martins, Astrid Avellan, Sandra Rodrigues, \\ Diana Salvador, Sónia Morais Rodrigues, and Tito Trindade \\ ACS Appl. Nano Mater., Just Accepted Manuscript • Publication Date (Web): 30 Jan 2020 \\ Downloaded from pubs.acs.org on January 30, 2020
}

\section{Just Accepted}

"Just Accepted" manuscripts have been peer-reviewed and accepted for publication. They are posted online prior to technical editing, formatting for publication and author proofing. The American Chemical Society provides "Just Accepted" as a service to the research community to expedite the dissemination of scientific material as soon as possible after acceptance. "Just Accepted" manuscripts appear in full in PDF format accompanied by an HTML abstract. "Just Accepted" manuscripts have been fully peer reviewed, but should not be considered the official version of record. They are citable by the Digital Object Identifier (DOI@). "Just Accepted" is an optional service offered to authors. Therefore, the "Just Accepted" Web site may not include all articles that will be published in the journal. After a manuscript is technically edited and formatted, it will be removed from the "Just Accepted" Web site and published as an ASAP article. Note that technical editing may introduce minor changes to the manuscript text and/or graphics which could affect content, and all legal disclaimers and ethical guidelines that apply to the journal pertain. ACS cannot be held responsible for errors or consequences arising from the use of information contained in these "Just Accepted" manuscripts. 


\title{
Composites of Biopolymers and $\mathrm{ZnO}$ NPs for Controlled Release of Zinc in Agricultural Soils and Timed Delivery for Maize
}

\author{
Natércia C.T. Martins ${ }^{\text {a,b* }}{ }^{*}$, Astrid Avellan ${ }^{a}$, Sandra Rodrigues ${ }^{a}$, Diana Salvador ${ }^{a}$, Sónia M. \\ Rodrigues $^{\mathrm{a}}$, Tito Trindade ${ }^{\mathrm{b}}$ \\ ${ }^{a}$ CESAM \& Department of Chemistry, University of Aveiro, Campus Universitário de \\ Santiago, 3810-193 Aveiro, Portugal \\ ${ }^{\mathrm{b}}$ CICECO \& Department of Chemistry, University of Aveiro, Campus Universitário de \\ Santiago, 3810-193 Aveiro, Portugal
}

\begin{abstract}
Zinc deficiency is a widespread micronutrient deficiency problem affecting crops worldwide. Unlike conventional ionic fertilizers ( $\mathrm{Zn}$ as salt or chelated forms), $\mathrm{Zn}$-based engineered nanomaterials (ENMs) have the potential to release $\mathrm{Zn}$ in a controlled manner, reducing $\mathrm{Zn}$ losses through leaching upon application to soil. In this work, composites made of biopolymers (microcrystalline cellulose, chitosan and alginate) and $\mathrm{ZnO}$ nanoparticles (4-65\% $\mathrm{Zn} \mathrm{w} / \mathrm{w}$ ) were prepared. Their potential for $\mathrm{Zn}$ controlled release was tested in four agricultural soils of distinct $\mathrm{pH}$ and organic matter content over 30 days. While conventionally used $\mathrm{Zn}$ salts leached from the soil resulting in very low $\mathrm{CaCl}_{2}$-extractable $\mathrm{Zn}$ concentration, $\mathrm{Zn}$ in $\mathrm{ZnO}$ NPs was less labile, and $\mathrm{ZnO}$-biopolymers maintained a better constant supply of $\mathrm{CaCl}_{2}$-extractable $\mathrm{Zn}$ than all other treatments. $\mathrm{ZnO} \mathrm{NPs} /$ alginate beads prepared by crosslinking with $\mathrm{CaCl}_{2}$ presented the slowest $\mathrm{Zn}$ release kinetics.

As assessed with maize plants grown in poor $\mathrm{Zn}$ acidic soil (LUFA 2.1, pH=5.2), this constant $\mathrm{Zn}$ release from $\mathrm{ZnO}$ NPs/alginate beads resulted in a steadier $\mathrm{Zn}$ concentration in the soil pore water over time. These results further indicate that $\mathrm{ZnO}$ NPs/alginate beads could meet the maize $\mathrm{Zn}$ needs while avoiding the early stage $\mathrm{Zn}$ toxicity induced by conventional $\mathrm{Zn}$ supplies, demonstrating that these ENMs are a sustainable way to supply $\mathrm{Zn}$ in a controlled manner in acidic soils. The impact of plant exudates on $\mathrm{Zn}$ bioavailability in the soil under maize-root influence (rhizosphere) is also discussed, underlying the need to study the fate of micronutrients in the rhizosphere to better predict its long-term bioavailability in bulk soils.
\end{abstract}


KEYWORDS: controlled release, micronutrients, biopolymers, composites, zinc oxide nanoparticles, maize rhizosphere

* Corresponding author. Tel.: +351 234401 405; fax: +351 234370084.

E-mail address: natercia@ua.pt (Natércia C.T. Martins) 


\section{INTRODUCTION}

In the last decades, nanotechnology has achieved great progress and it has been applied with success in several fields such as electronics, energy, environmental science and medicine. ${ }^{1-4}$ Nanotechnology applications in agriculture are increasing and need further exploration. ${ }^{5}$ Indeed, there are already some examples in the literature that show the potential of nanomaterials in improving agrochemical delivery, seed germination, plant growth and protection, pathogen detection and pesticide residue detection. ${ }^{6-12}$

Recently, nanomaterials were used in agricultural production to mitigate environmental problems caused by conventional intensive application of fertilizers. ${ }^{13,14}$ Due to a lack of synchronization between the release of minerals from bulk ionic fertilizers and uptake by plants, only a small part of the fertilizers applied to the soils are actually used by plants (30-50 \%). ${ }^{15}$ The remaining $\mathrm{Zn}$ applied forms nonbioavailable complexes in soils or it is removed by leaching or run-off causing negative environmental impacts. ${ }^{15-17}$ Using nanomaterials to apply essential micro and macro nutrients to plants is a promising fertilization method. ${ }^{18}$ Nanomaterials can be used to control the release of nutrients in soil-plant systems according to specific soil biochemical conditions, plant species and plant life cycle stages, allowing a reduction of nutrients loss and of fertilizers application rates. ${ }^{16,19}$

Essential plant nutrients include nitrogen, phosphate, potassium, calcium (macronutrients) iron, zinc and copper (micronutrients). $\mathrm{Zn}$ is crucial for plant growth and development as it takes part in a wide range of plant biochemical processes. Zinc plays a vital role in chlorophyll synthesis, in regulation of plant growth hormones, in maintaining healthy root systems, in activating enzymes and detoxifying free radicals, and in preserving tolerance to plant stressors. ${ }^{18,20}$ This element is also a very important nutrient for human health. In developing countries, where staple diets are plant-based, $\mathrm{Zn}$ deficiency is associated with growth retardation, impaired brain development and increased susceptibility to infectious diseases such as pneumonia and diarrhea. ${ }^{21}$

Wheat, rice and maize, are strategic crop plants for human nutrition and very sensitive to $\mathrm{Zn}$ deficiencies in soils. ${ }^{22}$ To grow without developing signs of $\mathrm{Zn}$ deficiencies, gramineous plants, and maize in particular, usually need around $1 \mathrm{mg}$ of extractable $\mathrm{Zn}$ per $\mathrm{Kg}$ of soil, ${ }^{23}$ or $50 \mu \mathrm{g}$ of $\mathrm{Zn}$ per $\mathrm{L}$ of soil pore water. ${ }^{14}$ This bioavailable zinc concentrations will depend on the soil $\mathrm{pH}$, oxide species and organic matter content. ${ }^{24,25}$

Zinc deficiency is a common problem in soils worldwide. ${ }^{26}$ To correct $\mathrm{Zn}$ deficiency and prevent losses on crops, fertilizers containing $\mathrm{Zn}$ are added to the soils. Water soluble salts such as $\mathrm{ZnSO}_{4}$ or $\mathrm{ZnCl}_{2}$ are often used as $\mathrm{Zn}$ fertilizers. ${ }^{27,28}$ These salts are a source of $\mathrm{Zn}$ readily 
available for plants; however, these nutrients can be easily lost by leaching and run-off from soils, particularly in acidic soils under heavy rainfall or intensive watering. $\mathrm{ZnO}$ in bulk or nanoparticles (NP) form can be an alternative to the use of ionic $\mathrm{Zn}$ forms as fertilizers. The effects of $\mathrm{ZnO}$ NPs on soils and crops has been recently subject of debate. There are a few papers reporting phytotoxicity of ZnO NPs; however, in the majority of these studies the experiments were designed using very high doses of $\mathrm{ZnO}$ NPs (higher than those used in conventional fertilization) and very short exposure times. ${ }^{29,30}$ In fact, there are also many studies that show that at low doses ZnO NPs are beneficial to crops. ${ }^{14,16,31}$ Moreover, a recent study ${ }^{32}$ demonstrated that in acidic soils, due to rapid dissolution of $\mathrm{ZnO}$ NPs, the risks of using $\mathrm{ZnO}$ NPs as fertilizer are not different from those of using ionic $\mathrm{Zn}$.

$\mathrm{ZnO}$ NPs dissolve relatively fast in acidic soils and can also be subject to aggregation leading to low $\mathrm{Zn}$ availability to crops and significant $\mathrm{Zn}$ losses by soil leaching and wash-off which result in $\mathrm{Zn}$ contamination of surface and groundwater. ${ }^{13,32} \mathrm{We}$ hypothesise that the immobilization of $\mathrm{ZnO}$ NPs onto polymeric substrates to form composites that release $\mathrm{Zn}$ in a slower and controlled manner can be a solution to these problems.

Biopolymers such as cellulose, alginate or chitosan can be interesting choices to be used as substrates for immobilization of nanoparticles to produce composite fertilizers because these are natural, low cost and biodegradable polymers. ${ }^{33}$ Moreover, some of these polymers are themselves beneficial to plants. This is the case of chitosan which is known to act as promoter of plant growth and as an activator of plant defense system. ${ }^{34}$ There are reports in literature concerning the use of biopolymers for controlled release of nutrients; however, the majority of the research is directed to macronutrients and the release tests are mainly done in water. ${ }^{35-37}$ Soil is a very complex matrix and the nature and composition of the soil have a significant impact on the behaviour and fate of the materials, particularly on dissolution. Tests of release of nutrients from polymer-based materials in realistic soil conditions are therefore most needed.

In this work, a series of composites of biopolymers and $\mathrm{ZnO}$ NPs were prepared (by the methods shown in Scheme 1), their potential as materials for the controlled release of $\mathrm{Zn}$ in agricultural soils was tested, and their impact towards maize plant was assessed. The materials were added to soils with distinct $\mathrm{pH}$ and organic matter content. A screening soil incubation study (7 days) was performed to determine the amount of labile $\mathrm{Zn}$ dissolved from the different $\mathrm{ZnO}$ NPs composites along time in different agricultural soils, using a soil $0.01 \mathrm{M} \mathrm{CaCl}_{2}$ extraction. ${ }^{38}$ The rate of $\mathrm{Zn}$ release was correlated with the type of polymeric matrix, method of preparation of the materials and characteristics of the soils. The extractability of $\mathrm{Zn}$ from the most promising material, ZnONPs/alginate beads, was further studied in an experiment with a 
soil incubation period of 30 days to evaluate the potential of this material to be used for controlled release of $\mathrm{Zn}$ in agricultural soils. Finally, the ability of $\mathrm{ZnO}$ NPs/alginate beads to supply $\mathrm{Zn}$ to maize plants was tested in soil LUFA 2.1, in comparison to $\mathrm{ZnO} \mathrm{NPs}$ and $\mathrm{ZnCl}_{2}$ for 30 days. We hypothesised that this material can potentially be used to control the effectivity of the application of $\mathrm{Zn}$ fertilizer in soil and thus reduce environmental collateral damages of Zn loss upon soil application.

\section{BIOPOLYMERS}
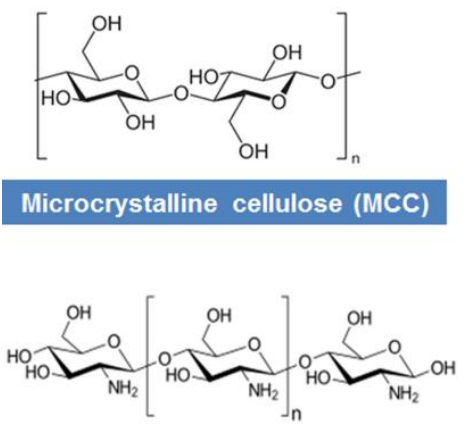

Chitosan (CH)

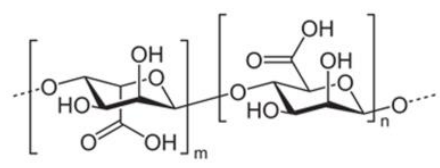

Alginate (ALG)
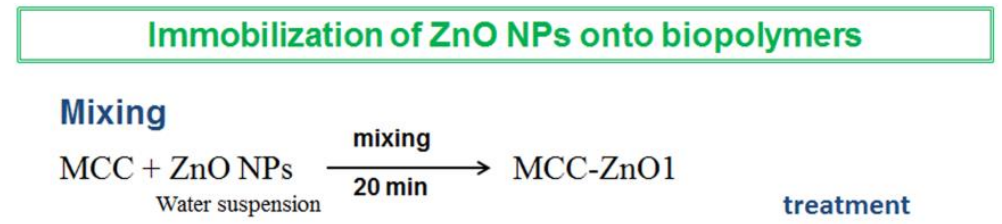

In situ synthesis

$\underset{\mathrm{CH}}{\mathrm{MCC}}+\underset{\text { (in methanol) }}{\mathrm{Zn}(\mathrm{OAc})_{2}} \stackrel{\text { reflux }}{\stackrel{\mathrm{NaOH}}{\mathrm{MCC}-\mathrm{ZnO} 2(30 \mathrm{~min})}} \begin{aligned} & \mathrm{MCC}-\mathrm{ZnO} 3(2 \mathrm{~h}) \\ & \mathrm{CH}-\mathrm{ZnO} 4(30 \mathrm{~min})\end{aligned}$

Gel of chitosan

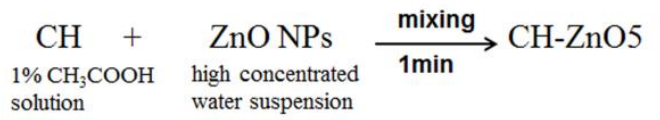

treatment with ALG

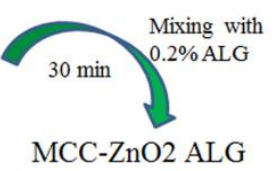

MCC-ZnO2 ALG

$\mathrm{CH}-\mathrm{ZnO} 4 \mathrm{ALG}$

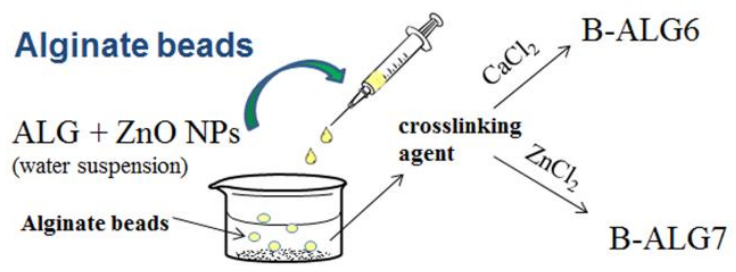

Scheme 1 Methods used for the preparation of the composites prepared in this work

\section{EXPERIMENTAL SECTION}

\subsection{Materials and analytical methods}

Microcrystalline cellulose (MCC), chitosan $(\mathrm{CH})$ (low molecular weight, degree of deacetylation 75-85\%) and alginic acid sodium salt from brown algae (ALG) were purchased from Sigma-Aldrich and were used as received. Calcium chloride (>99\%, ACS grade), Zinc chloride ( $>98 \%$, ACS grade) and zinc acetate dihydrate ( $>98 \%)$ were obtained by Merck. Commercial ZnO NPs were purchased from Nanostructure \& Amorphous Materials Inc., USA (99.5\% purity, $20 \mathrm{~nm}$ diameter size as reported by the manufacturer).

Four soils were used in this study: standard agricultural soils LUFA 2.1 and LUFA 2.2 were purchased from LUFA Speyer in Germany; two agricultural calcareous soils were collected in 
south Portugal (soil codes: "DE" and "VV"; soils were collected at the 0-20 cm layer, using plastic spades and transported to the laboratory for pre-treatment and analysis). The LUFA soils were included because they are commonly used in metal bioavailability studies and therefore would be easier to compare our results with other found in literature. Soil characterization was performed on the $<2 \mathrm{~mm}$ air-dried soil fraction. The $\mathrm{pH}$ of samples was measured using a glass electrode in a 1:5 (v/v) suspension of ashes/soils in $\mathrm{CaCl}_{2}$ (according to ISO 10390:1994). A laser diffraction particle size analyser (Coulter LS230) was used to determine clay, silt and sand content for ashes and soils (limit of detection $=0.040 \mu \mathrm{m})$. Organic carbon $(\mathrm{OrgC})$ in soils was determined after addition of hydrochloric acid to re-move carbonates (ISO 10694:1995). The water holding capacity (WHC) was determined by saturating the air-dried soils in a cylinder during 24 hours. The cylinder was then placed on an absorbent membrane until the excess water was drawn away by gravity. Once equilibrium was reached (24-48 hours), the WHC was calculated based on the weight of the water held in the sample vs. the sample dry weight. The pseudo-total content of $\mathrm{Zn}$ in soils was determined by aqua regia (AR) digestion (according to ISO 11466:1995) and analysis by ICP-MS (Agilent 7700). Soil extractable Zn was determined by extraction with $0.01 \mathrm{M} \mathrm{CaCl}_{2}$ (1:10 weight:volume ratio) and analysis by ICP-MS. Samples for analysis by ICP-MS were acidified with $20 \% \mathrm{HNO}_{3}$ (final $\mathrm{HNO}_{3}$ concentration, $1 \%$ ) kept at $4^{\circ} \mathrm{C}$ and analyzed within 1-4 days after collection. Instrument calibration standards were prepared in the same acid matrix as the soil extracts and spike recovery samples were included in all analyses. Before analysing by ICP-MS, the samples were diluted in ultra-pure water $(1: 10 \mathrm{v} / \mathrm{v})$. The detection limit for this $\mathrm{Zn}$ analysis was $(8 \mu \mathrm{g} / \mathrm{L})$. All analysis were performed in triplicate.

LUFA 2.1 is a loamy sand soil containing 3 wt $\%$ clay, 11 wt $\%$ silt, and 86 wt $\%$ sand. It has an organic carbon content of $0.71 \pm 0.08 \%$, a pH $\left(0.01 \mathrm{M} \mathrm{CaCl}_{2}\right)$ of 5.2 and maximum water holding capacity of $32 \%$. LUFA 2.2. is a sandy loam soil containing $8 \mathrm{wt} \%$ clay, $15.8 \mathrm{wt} \%$ silt, and 76.2 wt $\%$ sand. It has an organic carbon content of $1.61 \pm 0.15 \%$ and a $\mathrm{pH}(0.01 \mathrm{M}$ $\mathrm{CaCl}_{2}$ ) of 6.1 and maximum water holding capacity of $43 \%$. Moreover, these soils have a low content of extractable $\mathrm{Zn}\left(0.86 \mathrm{mg} / \mathrm{kg}\right.$ for LUFA 2.1 and $0.26 \mathrm{mg} / \mathrm{kg}$ for LUFA $2.2, \mathrm{CaCl}_{2}$ extraction) making background interference minimal.

Soil DE has an organic carbon content of $7.2 \%$, a $\mathrm{pH}\left(0.01 \mathrm{M} \mathrm{CaCl}_{2}\right)$ of 7.0 , a maximum water holding capacity of $48 \%$ and it contains $0.1 \mathrm{wt} \%$ clay. Soil VV has an organic carbon content of $0.9 \%$, a $\mathrm{pH}\left(0.01 \mathrm{M} \mathrm{CaCl}_{2}\right)$ of 6.9 , a maximum water holding capacity of $27 \%$ and contains 10.4 wt \% clay. The concentration of extractable $\mathrm{Zn}$ in soils DE and VV was under the detection limit of ICP-MS $(8 \mu \mathrm{g} / \mathrm{L})$. 
All the dry soils (without zinc amendments) were sterilized by autoclaving $\left(121^{\circ} \mathrm{C}\right) 1 \mathrm{~h}$ prior to use in the incubation tests.

All chemicals were of analytical grade or better and all solutions were prepared using ultrapure water (MilliQ water).

\subsection{Preparation of nanocomposites}

Table 1 presents the list of the composites prepared in this work along with the method used for their synthesis and the respective $\mathrm{Zn}$ content (as determined by atomic absorption spectroscopy following digestion). The next sections present a detail description of the methods of preparation of the composites.

\subsubsection{Composite obtained by mixing MCC with ZnO NPs}

Commercial ZnO NPs (0.018 g) were dispersed in $50 \mathrm{ml}$ of Milli-Q water and the resulting suspension was sonicated using an ultrasonic bath for $5 \mathrm{~min}$. The suspension was placed under magnetic stirring and then $0.2 \mathrm{~g}$ of MCC were added. After $20 \mathrm{~min}$ of mixing, the resulting nanocomposite (identified as MCC-ZnO1) was collected by filtration, thoroughly washed with distilled water and dried under vacuum in a desiccator with silica gel overnight.

\subsubsection{In situ synthesis of ZnO NP on biopolymers}

$\mathrm{ZnO}$ NPs were grown at polymers surfaces (MCC or $\mathrm{CH}$ ) by zinc acetate hydrolysis with $\mathrm{NaOH}$ in alcoholic medium in the presence of water. The method used was an adaptation of the procedure described by $\mathrm{Wu}$ et al $^{39}$ for the synthesis of $\mathrm{ZnO}$ NPs. In the present study the reaction was performed in the presence of the biopolymers. In this preparation, $0.5 \mathrm{~g}$ of biopolymer were mixed with $40 \mathrm{ml}$ of a methanolic solution of $\mathrm{Zn}(\mathrm{OAc})_{2} .2 \mathrm{H}_{2} \mathrm{O}\left(3.8 \times 10^{-2} \mathrm{M}\right)$ at room temperature during 1 hour. The suspension was then refluxed for 45 min under stirring and $10 \mathrm{ml}$ of water were added followed by dropwise addition of $30 \mathrm{ml}$ of $\mathrm{NaOH}$ methanolic solution $(0.1 \mathrm{M})$. After 30 minutes or 2 hours of reflux the reaction was stopped, and the suspension was allowed to cool to room temperature. The final composites were isolated by filtration, washed two times with $10 \mathrm{ml}$ of ethanol and dried overnight under vacuum in a desiccator with silica gel. This procedure generated the composites here identified as MCC$\mathrm{ZnO} 2$ (30 min reaction), $\mathrm{MCC}-\mathrm{ZnO} 3$ (2h reaction) and $\mathrm{CH}-\mathrm{ZnO} 4$ (30 min reaction). 


\section{Table1}

List of all composites prepared

\begin{tabular}{|c|c|c|c|c|c|}
\hline Sample & Matrix & Method & $\begin{array}{c}\text { ZnO NPs } \\
\text { diameter }^{\text {a }} \\
(\mathrm{nm})\end{array}$ & $\begin{array}{c}\mathrm{Zn}^{\mathrm{c}} \\
(\% \mathrm{w} / \mathrm{w})\end{array}$ & $\begin{array}{c}\text { Deposition } \\
\text { efficiency } \\
(\%)\end{array}$ \\
\hline MCC-ZnO1 & $\mathrm{MCC}$ & Mixing MCC with ZnO NPs & $87 \pm 24^{b}$ & $3.6 \pm 0.6$ & $54^{\mathrm{d}}$ \\
\hline $\mathrm{MCC}-\mathrm{ZnO} 2$ & $\mathrm{MCC}$ & $\begin{array}{l}\text { In situ synthesis of } \mathrm{ZnO} \text { NPs, } \\
30 \text { min of reaction }\end{array}$ & $129 \pm 39$ & $13.5 \pm 2.6$ & $85^{\mathrm{e}}$ \\
\hline $\begin{array}{l}\mathrm{MCC}-\mathrm{ZnO} 2 \\
\mathrm{ALG}\end{array}$ & MCC & $\begin{array}{c}\text { Treatment of } \mathrm{MCC}-\mathrm{ZnO} 2 \\
\text { with alginate }\end{array}$ & $129 \pm 39$ & $12.9 \pm 2.5$ & ---- \\
\hline $\mathrm{MCC}-\mathrm{ZnO} 3$ & $\mathrm{MCC}$ & $\begin{array}{c}\text { In situ synthesis of } \mathrm{ZnO} N P s \text {, } \\
2 \mathrm{~h} \text { of reaction }\end{array}$ & $120-400$ & $15.1 \pm 1.8$ & $94^{\mathrm{e}}$ \\
\hline $\begin{array}{l}\mathrm{MCC}-\mathrm{ZnO} 3 \\
\text { ALG }\end{array}$ & $\mathrm{MCC}$ & $\begin{array}{c}\text { Treatment of MCC- } \mathrm{ZnO} 3 \\
\text { with alginate }\end{array}$ & $120-400$ & $13.2 \pm 1.5$ & ----- \\
\hline $\mathrm{CH}-\mathrm{ZnO} 4$ & $\mathrm{CH}$ & $\begin{array}{c}\text { In situ synthesis of } \mathrm{ZnO} N \mathrm{NP} \text {, } \\
30 \text { min of reaction }\end{array}$ & $113 \pm 33$ & $12.9 \pm 1.6$ & $81^{\mathrm{e}}$ \\
\hline G-CH-ZnO5 & $\mathrm{CH}$ & Gel of chitosan and $\mathrm{ZnO}$ NPs & $87 \pm 24^{b}$ & $64.6 \pm 7.0$ & $87^{\mathrm{d}}$ \\
\hline B-ALG6 & ALG & $\begin{array}{l}\mathrm{ZnO} \text { NPs/alginate beads } \\
\text { Crosslinking with } \mathrm{CaCl}_{2}\end{array}$ & $87 \pm 24^{b}$ & $11.8 \pm 1.1$ & $88^{\mathrm{d}}$ \\
\hline B-ALG7 & ALG & $\begin{array}{l}\mathrm{ZnO} \text { NPs/alginate beads } \\
\text { Crosslinking with } \mathrm{ZnCl}_{2}\end{array}$ & $87 \pm 24^{\mathrm{b}}$ & $33.5 \pm 3.5$ & $>100^{d}$ \\
\hline
\end{tabular}

a based on SEM images of at least 150 particles (results are presented as mean \pm standard deviation or size range); Only two composites (MCC-ZnO3 and MCC-ZnO3 ALG) exhibited significantly higher diameter $(\mathrm{p}<0.05)$ than the remaining ones.; ${ }^{\mathrm{b}}$ commercial nanoparticles; ${ }^{\mathrm{c}}$ results are presented as mean \pm standard deviation ( 3 replicates of each material); ${ }^{\mathrm{d}}$ deposition efficiency $=$ ratio between the mean mass of $\mathrm{Zn}$ measured in the composite and the mass of $\mathrm{Zn}$ in the suspension of $\mathrm{ZnO} N P s ;{ }^{\mathrm{e}}$ deposition efficiency = ratio between the mean mass of $\mathrm{Zn}$ measured in the composite and the expected mass of $\mathrm{Zn}$ (considering a yield of $100 \%$ in the in situ synthesis of $\mathrm{ZnO} \mathrm{NPs}$ ).

\subsubsection{Alginate treated MCC-ZnO nanocomposites}

Composites MCC-ZnO2 and MCC-ZnO3, obtained by in situ synthesis, were further treated with a solution of alginate. Typically, $0.2 \mathrm{~g}$ of MCC-ZnO2 or MCC-ZnO3 composites were treated with $50 \mathrm{ml}$ of a solution containing $0.2 \mathrm{~g}$ of sodium alginate with stirring for 1 hour. 
The resultant composites, identified as MCC-ZnO2 ALG and MCC-ZnO3 ALG, were then isolated by filtration, thoroughly washed with distilled water and dried under vacuum in a desiccator with silica gel overnight.

\subsubsection{Gel of chitosan and ZnO NPs}

A gel of chitosan and ZnO NPs was prepared by the adaptation of the method reported by Vasile et al. ${ }^{40}$. Chitosan (0.025 g) was dissolved in $10 \mathrm{ml}$ of acetic acid solution (1\%). Commercial ZnO NPs $(0.3 \mathrm{~g})$ were suspended in $5 \mathrm{ml}$ of distilled water and sonicated using an ultrasonic bath for $5 \mathrm{~min}$. The suspension was quickly added to a $10 \mathrm{ml}$ solution of chitosan $(0.025 \mathrm{~g})$ in acetic acid (1\%) under magnetic stirring. In a few seconds a $\mathrm{ZnO}$-chitosan gel was formed. The gel with a consistency of a gelatine pudding was removed from beaker and cut in pieces that were dried at room temperature. The resulting films were ground in a mortar to obtain a powder (G-CHZnO5).

\subsubsection{Alginate beads containing ZnO NPs}

Sodium alginate $(0.75 \mathrm{~g})$ was stirred in $50 \mathrm{ml}$ distilled water for 1 hour to ensure the formation of a homogeneous solution. ZnO NPs $(0.150 \mathrm{~g})$ were then added to the alginate solution and the mixture was left under continuous stirring. The milky mixture was transferred to a syringe and added drop by drop into a beaker containing $100 \mathrm{ml}$ of $0.25 \mathrm{M}$ solution of the crosslinking agent $\left(\mathrm{CaCl}_{2}\right.$ or $\left.\mathrm{ZnCl}_{2}\right)$ under moderate stirring. The resulting alginate beads were allowed to stay for $30 \mathrm{~min}$ in the crosslinking agent solution and then were separated by filtration, thoroughly washed with distilled water and dried at $30{ }^{\circ} \mathrm{C}$ for one day. For soil tests the beads were ground in a mortar to obtain a powder. By this method, composites B-ALG6 (crosslinking with $\mathrm{CaCl}_{2}$ ) and B-ALG7 (crosslinking with $\mathrm{ZnCl}_{2}$ ) were obtained.

\subsection{Materials characterization}

Scanning electron microscopy (SEM) images were obtained with a Hitachi S4100 or a Hitachi SU-70 instrument fitted with an energy dispersive spectroscopy (EDS) accessory (EDSdetector: Bruker AXS; software: Quantax). Samples were deposited on carbon tape and coated with carbon before SEM analysis. Transmission electron microscopy (TEM) was 
performed with a Hitachi H-9000 or a JEOL 2200FS electron microscope equipped with Oxford Energy Dispersive X-rays (EDS) detector and in-column Omega filter, operated at $300 \mathrm{kV}$. The samples for TEM were prepared by depositing a drop of a diluted suspension of the materials in ultra-pure water onto the surface of an Agar Scientific carbon-coated copper grid and then allowing the solvent to evaporate. To calculate the mean size of ZnO NPs based on SEM or TEM images at least 150 particles were measured.

The total $\mathrm{Zn}$ concentration in the composite materials was evaluated by atomic absorption spectroscopy (AAS) using a Thermo Scientific ICE 3000 series AA spectrometer (detection limit: $50 \mu \mathrm{g} / \mathrm{L})$. Before AAS the samples were submitted to acid digestion with $\mathrm{HNO}_{3}(68 \%)$ in a microwave oven. Instrument calibration standards were prepared in the same acid matrix as the soil extracts. All analysis were performed in triplicate.

Zeta potential measurements were performed using a Zeta Sizer Nano Series (Malvern) equipment. The optical spectra were recorded using a Jasco V-560 UV/VIS spectrophotometer; for the solid samples the spectra were recorded in the diffuse reflectance mode using $\mathrm{MgO}$ as reference. Powder X-rays Diffraction (XRD) patterns of the solid samples were recorded with a Philips X'Pert instrument operating with $\mathrm{Cu}-\mathrm{K} \alpha$ radiation $(\lambda=1.543178 \AA$ ) at $40 \mathrm{kV}$ and 50 mA. FTIR spectra (128 scans at a resolution of $4 \mathrm{~cm}^{-1}$ ) were collected with a Mattson 7000 spectrometer coupled to a horizontal attenuated total reflectance (ATR) cell.

\subsection{Soil amendment and incubation}

Soils LUFA 2.1, LUFA 2.2, DE and VV were amended with $\mathrm{ZnO} \mathrm{NPs}, \mathrm{ZnCl}_{2}$ or biopolymer composites loaded with ZnONPs to obtain a Zn concentration of $100 \mathrm{mg} / \mathrm{kg}$ dry soil.

$\mathrm{ZnO}$ NPs and $\mathrm{ZnO}$ NPs composite powders were dispersed in Milli-Q water $(\mathrm{pH}=7)$ and the suspensions were then sonicated in an ultrasonic bath for $2 \mathrm{~min}$. The dispersed nanomaterials were then immediately added to soil. $\mathrm{ZnCl}_{2}$ powder was dissolved in Milli-Q water before being amended to the soil. The amount of Milli-Q water added to each soil was the necessary to ensure that each soil was at $50 \%$ of their maximum water holding capacity after amendment.

First, a screening test was done in acid soils LUFA 2.1 and LUFA 2.2 with all the materials for two incubation times 1 and 7 days. Typically, $4 \mathrm{ml}$ or $5.6 \mathrm{ml}$ of $\mathrm{ZnCl}_{2}$ solution or $\mathrm{ZnO}$ NPs materials suspensions were added to $25 \mathrm{~g}$ of dried LUFA 2.1 or LUFA 2.2 soils respectively. $18 \mathrm{~g}$ (dry weight) of each amended soil were then divided into 6 centrifuge tubes ( 3 replicates, 2 incubation periods) with $3 \mathrm{~g}$ of soil each. The soil samples were then incubated under aerobic conditions at room temperature for 1 and 7 days before being extracted. The moisture content 
of the soil samples was kept at $50 \%$ of their maximum water holding capacity by daily additions of MilliQ water.

The material that presented the lowest $\mathrm{Zn}$ release (B-ALG6) was tested in a period of 30 days of incubation in acid soils LUFA 2.1 and LUFA 2.2 and neutral soils (DE and VV) in order to better understand the role of $\mathrm{pH}$ on $\mathrm{Zn}$ release from this composite. In this case, soil samples were incubated under aerobic conditions at room temperature for 1, 2, 4, 7, 15 and 30 days before being extracted.

\subsection{Maize culture in LUFA 2.1 soil amended with different $\mathrm{Zn}$ sources}

Maize seeds (Zea Mays) were surface sterilized with bleach, thoroughly rinsed with deionized water and germinated on plate with saturated humidity in the dark at $20^{\circ} \mathrm{C}$ for 5 days. LUFA 2.1 soil (900 g) was amended with different treatments, as described above. Homogenisation of the soil with the different treatments was done by stirring the soil (3 times during 5 minutes) after the addition of the materials suspensions to ensure for a good homogenisation of the treatments. Soils were prepared to reach $50 \%$ of the maximum water holding capacity. After homogenisation, the soils of the different treatments were transferred into pots. In the middle of each pot, a filtration device was horizontally placed. These samplers $\left(\text { Rhizon }{ }^{\circledR} \text { Flex, } 5 \mathrm{~cm}\right)^{41}$ are made of polyethersulfone membranes of $0.12-0.17 \mu \mathrm{m}$ nominal pore size, connected to a luer lock through a $30 \mathrm{~cm}$ long PVP-PE tubing, that allowed for pore water sampling outside of the pot, without disturbing the soil. These membrane filters are made of inert polymers with no ion exchange properties to minimize sorption. Pore water (4-7 ml) was sampled from each pot 2, 6, 10, 24 and 29 days after the seed transfer. An aliquot was used for $\mathrm{pH}$ measurement, and the rest was acidified $\left(2 \% \mathrm{HNO}_{3}\right)$ and stored at $4{ }^{\circ} \mathrm{C}$ for total $\mathrm{Zn}$ measurement by ICP-MS, as described in section 2.1 .

A rope made of $100 \%$ cotton connecting the soil to a nutritive solution allowed, through capillary exchanges, to maintain the soil humidity constant over time. The nutritive solution used was $1 / 4$ strength Hoagland solution, ${ }^{42}$ prepared without Zinc micronutrients to ensure that the plant will not undergo other deficiencies than $\mathrm{Zn}$.

Four maize seedlings were transferred per pot of $900 \mathrm{~g}$ of soil amended with $30 \mathrm{ppm}$ or 100 ppm (as $\mathrm{Zn}$ ) of either $\mathrm{ZnCl}_{2}, \mathrm{ZnO}$ NPs or $\mathrm{ZnO}$ NPs/alginate (B-ALG6), or in a control soil (ultrapure water, UP). Alginate controls with similar alginate concentration as the B-ALG6 30 ppm and $100 \mathrm{ppm}$ treatments were also run. These resulted in 9 treatments and four maize plants per treatments, namely water, ALG 30eq, ALG 100eq, $\mathrm{ZnCl}_{2} 30$ ppm, $\mathrm{ZnCl}_{2} 100$ ppm, ZnO 30 
ppm, ZnO 100 ppm, B-ALG6 30 ppm, B-ALG6 100 ppm. The plants were then grown under Tubo T8 G13 58W 5000LM 6500K fluorescence lamps under a 16:8 light:night photoperiod over 29 days.

At the end of the experiment, all the plants were collected. Shoots were separated from the root system and pictures were taken. Shoots and roots were dried at $60^{\circ} \mathrm{C}$ during $48 \mathrm{~h}$ to assess for dry biomass. Length of the leaves was measured on the plant pictures using the ImageJ software. Shoot density was calculated as a ratio of the biomass divided by the total leaves length of each plant.

Bulk soil was separated from the rhizosphere soil following previous established procedures, ${ }^{43}$ dried at $60^{\circ} \mathrm{C}$ until the dry mass didn't change and used for $\mathrm{CaCl}_{2}$ extraction as described below for $\mathrm{pH}$ measurements and $\mathrm{Zn}$ concentration measurements.

\subsection{Extraction test to determine the extractable pool of $\mathrm{Zn}$ in amended soil}

After 1,2, 4, 7, 15 or 30 days of incubation without plants, and 30 days of incubation with plants, dry soil samples of soil LUFA 2.1, LUFA 2.2, DE and VV amended with ZnO NPs, $\mathrm{ZnCl}_{2}$ or biopolymer composites loaded with ZnONPs were extracted in triplicate with a 1:10 soil: $\mathrm{CaCl}_{2}$ ratio using a $0.01 \mathrm{M} \mathrm{CaCl}_{2}$ solution in centrifuge tubes. Centrifuge tubes were laid horizontally and shaken for 2 hours, using a reciprocal shaker at $180 \mathrm{rpm}$. After extraction, all samples were centrifuged at $1022 \mathrm{~g}$ for $10 \mathrm{~min}$, and the supernatants were filtered using a 0.2 $\mu \mathrm{m}$ PTFE syringe filter. It should be noticed that at first supernatants were filtered with $0.2 \mu \mathrm{m}$ and $3 \mathrm{kDa}$ filters and it was observed that $\mathrm{Zn}$ content of the extracts were similar in the two cases. Therefore, in the following experiments only $0.2 \mu \mathrm{m}$ filters were used. Soil blanks (no Zn treatment, only ultra-pure water added to ensure the same moisture content) were used as controls. The $\mathrm{pH}$ values of $\mathrm{CaCl}_{2}$ extracts were measured. After that, all extracts were acidified with a $20 \%$ solution of $\mathrm{HNO}_{3}$ (final $\mathrm{HNO}_{3}$ concentration of 2\%) and analyzed for $\mathrm{Zn}$ concentration by ICP-MS, as described in Section 2.1 .

\subsection{Statistical analysis}

The software SPSS 24.0 by IBM for MacOS was used for calculation of descriptive statistics and for statistical analysis of data. For the experiment without maize, comparison of results for different materials and respective $\mathrm{Zn}$ release in soil was based on analysis of variance (ANOVA) provided by the General Linear Model (univariate analysis). Bonferroni post hoc 
tests were applied to explore differences between group means. To compare plant biomass and density, ANOVA was done using a Tukey test.

\section{RESULTS AND DISCUSSION}

\subsection{Materials characterization}

SEM analysis of commercial ZnO NPs powders showed that the particles were nearly spheroidal with mean diameter of $87 \pm 24 \mathrm{~nm}$ (Fig. S1, supporting information). TEM analysis of a diluted suspension of $\mathrm{ZnO}$ NPs in water was also performed (Fig. S2, supporting information). The diameter of the nanoparticles calculated from TEM images was in good agreement with the obtained by SEM, which also showed that the ZnO NPs did not aggregate in water (at least in the time of preparation of the suspension: $5 \mathrm{~min}$ ). The size distribution of $\mathrm{ZnO}$ NPs calculated from SEM and TEM images was higher than that reported by the manufacturer $(20 \mathrm{~nm})$. This discrepancy could be attributed to some aggregation of metal oxide nanoparticles or to low accuracy of the size values reported. ${ }^{44}$ Zeta $(\zeta)$ potential measurements of a $200 \mathrm{mg} \mathrm{L}^{-1} \mathrm{ZnO}$ NPs suspension showed that the nanoparticles are positively charged (+ $22.1 \pm 0.379 \mathrm{mV}$ at $\mathrm{pH}$ 7.2). Powder XRD pattern of ZnO NPs (Fig. S3, supporting information) presents the characteristic peaks of wurtzite crystal structure (JCPDF No $36-1451$ ). The UV-Vis reflectance spectrum of $\mathrm{ZnO}$ NPs showed the characteristic absorption edge associated to the energy gap of $\mathrm{ZnO}$, with maximum of absorption at $360 \mathrm{~nm}$ (Fig. S4, supporting information). The absorption maximum of $\mathrm{ZnO}$ NPs was blue shifted relative to bulk $\mathrm{ZnO}$ (380 nm) due to the quantum confinement effect of the $\mathrm{ZnO}$ nanostructure. ${ }^{45}$

Several composites of biopolymers (microcrystalline cellulose, chitosan and alginate) and $\mathrm{ZnO}$ NPs were produced using different methodologies (Table 1, experimental section).

The MCC-ZnO1 composite was prepared by mixing MCC with the commercial nanoparticles. The efficiency of the deposition of ZnO NPs on MCC fibers was low (54\%) and the $\mathrm{Zn}$ content on the final composite was only $3.6 \%(\mathrm{w} / \mathrm{w})$. The low deposition efficiency could be related with the fact that positively charged $\mathrm{ZnO}$ NPs can only bind to the negatively charged MCC fibers (zeta potential of $-18.6 \mathrm{mV}$ at $\mathrm{pH}$ 7.2) by weak electrostatic forces. SEM (Fig.1), EDS (Fig. S5, supporting information) and XRD (Fig. S6, supporting information) analysis of MCC-ZnO1 sample confirmed the presence of $\mathrm{ZnO}$ NPs over MCC fibers; however, the nanoparticles do not fully cover the polymer surface. Moreover, the deposition of the $\mathrm{ZnO}$ NPs seems to be non-homogeneous since it is possible to find areas in the matrix with low (Fig. 
1a) and high density of nanoparticles (Fig. 1b). Areas with high density of nanoparticles were attributed to the existence of a higher number of carboxyl groups (which have a negative charge) on MCC fibers. XRD of the sample (Fig. S6, supporting information) shows the characteristic Bragg reflections of $\mathrm{ZnO}$ (wurtzite) $\left(2 \theta=31.8^{\circ}, 34.6^{\circ}, 36.4^{\circ}, 47.8^{\circ}, 56.7^{\circ}, 63.1^{\circ}\right.$ and $\left.68.3^{\circ}\right)$ and of MCC (cellulose I) $\left(2 \theta=14.3^{\circ}, 15.9^{\circ}, 22.6^{\circ}\right)$. The UV-vis reflectance spectrum of the nanocomposite showed the presence of the absorption edge associated to the energy gap of $\mathrm{ZnO}$, with an onset of absorption close to that observed in the spectrum of commercial $\mathrm{ZnO}$ NPs (Fig. S4, supporting information).
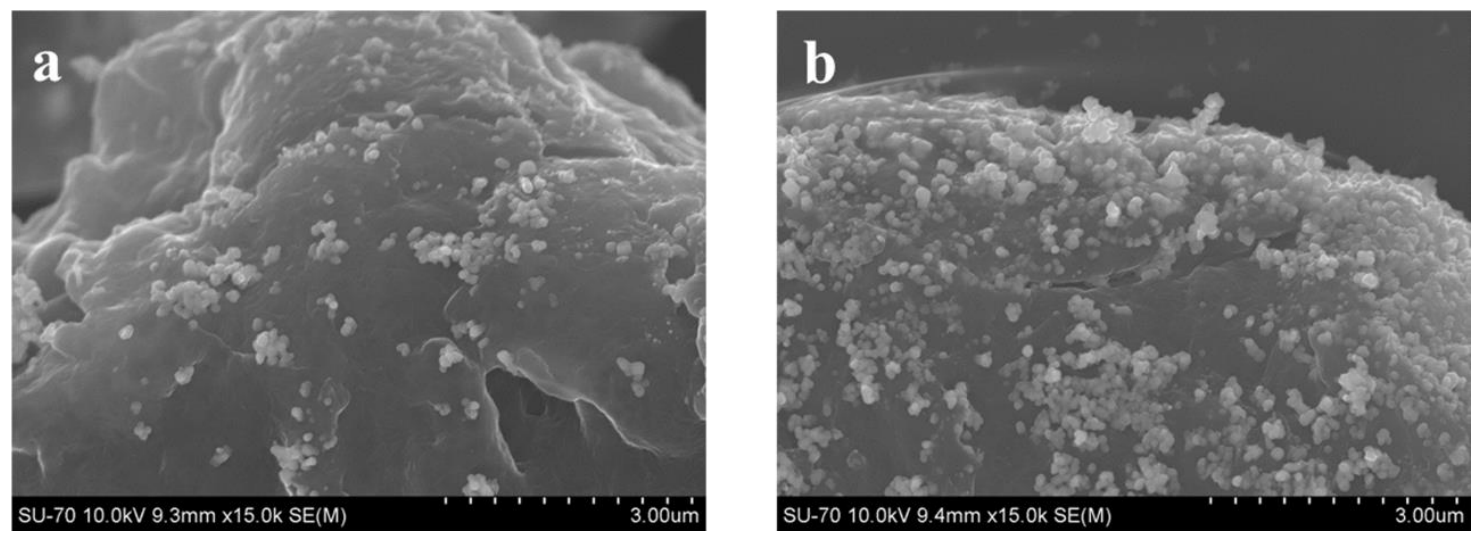

Fig. 1. SEM images of MCC-ZnO1 composite showing areas with low (a) and high (b) density of $\mathrm{ZnO}$ NPs.

In situ synthesis of $\mathrm{ZnO}$ NPs performed in the presence of biopolymers generated composites with higher content of $\mathrm{Zn}$ than those prepared by mixing the biopolymer with $\mathrm{ZnO}$ NPs (MCC-ZnO1). Using different biopolymers ( $\mathrm{MCC}$ or $\mathrm{CH})$ and variable reaction times (30 min or $2 \mathrm{~h}$ ) three different composites were obtained with in situ synthesis of $\mathrm{ZnO}$ NPs (MCC$\mathrm{ZnO} 2, \mathrm{MCC}-\mathrm{ZnO} 3$ and $\mathrm{CH}-\mathrm{ZnO} 4)$. SEM analysis of the nanocomposites showed that the nanoparticles tended to agglomerate at the surface of the polymer forming a compact ZnO NPs coating (Fig. 2). Unlike the commercial nanoparticles used in this work, which are nearly spherical-shape, the ZnO NPs obtained by in situ synthesis had a disc shape, with some of the NPs showing hexagonal facets. For the same time of reaction (30 min), in situ synthesis of $\mathrm{ZnO}$ NPs onto MCC or Chitosan $(\mathrm{CH})$ occurred in a similar way. $\mathrm{ZnO}$ nanodiscs with similar diameter were obtained $(129 \pm 39 \mathrm{~nm}$ for $\mathrm{MCC}$ and $113 \pm 33 \mathrm{~nm}$ for $\mathrm{CH}$; values represent mean \pm standard deviation) and the $\mathrm{Zn}$ content of the composites was not very different (13.5 for $\mathrm{MCC}$ and $12.9 \%$ for $\mathrm{CH}$ ). Moreover, the $\mathrm{ZnO}$ NPs deposition efficiencies for MCC-ZnO2 and $\mathrm{CH}-\mathrm{ZnO} 4$ were also similar, $85 \%$ and $81 \%$ respectively. This suggests that the type of matrix is not determinant in the in situ synthesis and growth of the ZnO NPs. By contrast, the reaction 
time had relevant influence on the synthesis and deposition of ZnO NPs on the polymer. When the reaction time was increased from 30 min to 2 hours, larger $\mathrm{ZnO}$ particles were formed and the composite obtained showed higher $\mathrm{Zn}$ content $(15.1 \%)$ and higher deposition efficiency (94\%). For the composites obtained by $30 \mathrm{~min}$ of reaction, the size of the nanoparticles was fairly uniform. For the composites prepared by 2 hour reaction, particles of variable diameters were formed (from 120 to $400 \mathrm{~nm}$ ) and in some areas, the formation of a continuous $\mathrm{ZnO}$ film was observed (Fig. 2d). This means that long times of reaction favour a non-homogeneous growth of nanoparticles on the biopolymer. Although most of the nanoparticles were found on the surface of the polymer, it was possible to observe the presence of ZnO NPs also inside the cellulose fibers through the TEM analysis of the sample MCC-ZnO2 (Fig. S7, supporting information). This could be explained by considering that $\mathrm{Zn}$ precursor can penetrate onto the fibers and then undergo hydrolysis in the presence of $\mathrm{NaOH}$ solution producing $\mathrm{ZnO}$ NPs. Other authors also observed the formation of nanoparticles inside cellulose films or within regenerated cellulose fibers after in situ synthesis of $\mathrm{ZnO} N P s .{ }^{46,47}$ XRD pattern of the samples showed peaks correspondent to the polymers and to $\mathrm{ZnO}$ wurtzite phase confirming the presence of ZnO NPs on the composites (Fig. S8, supporting information). As expected, the $\mathrm{UV}-\mathrm{Vis}$ spectra of $\mathrm{MCC}-\mathrm{ZnO} 2, \mathrm{MCC}-\mathrm{ZnO} 3$ and $\mathrm{CH}-\mathrm{ZnO} 4$ presented the absorption edge associated to the energy gap of $\mathrm{ZnO}$ (Fig. S4, supporting information). 

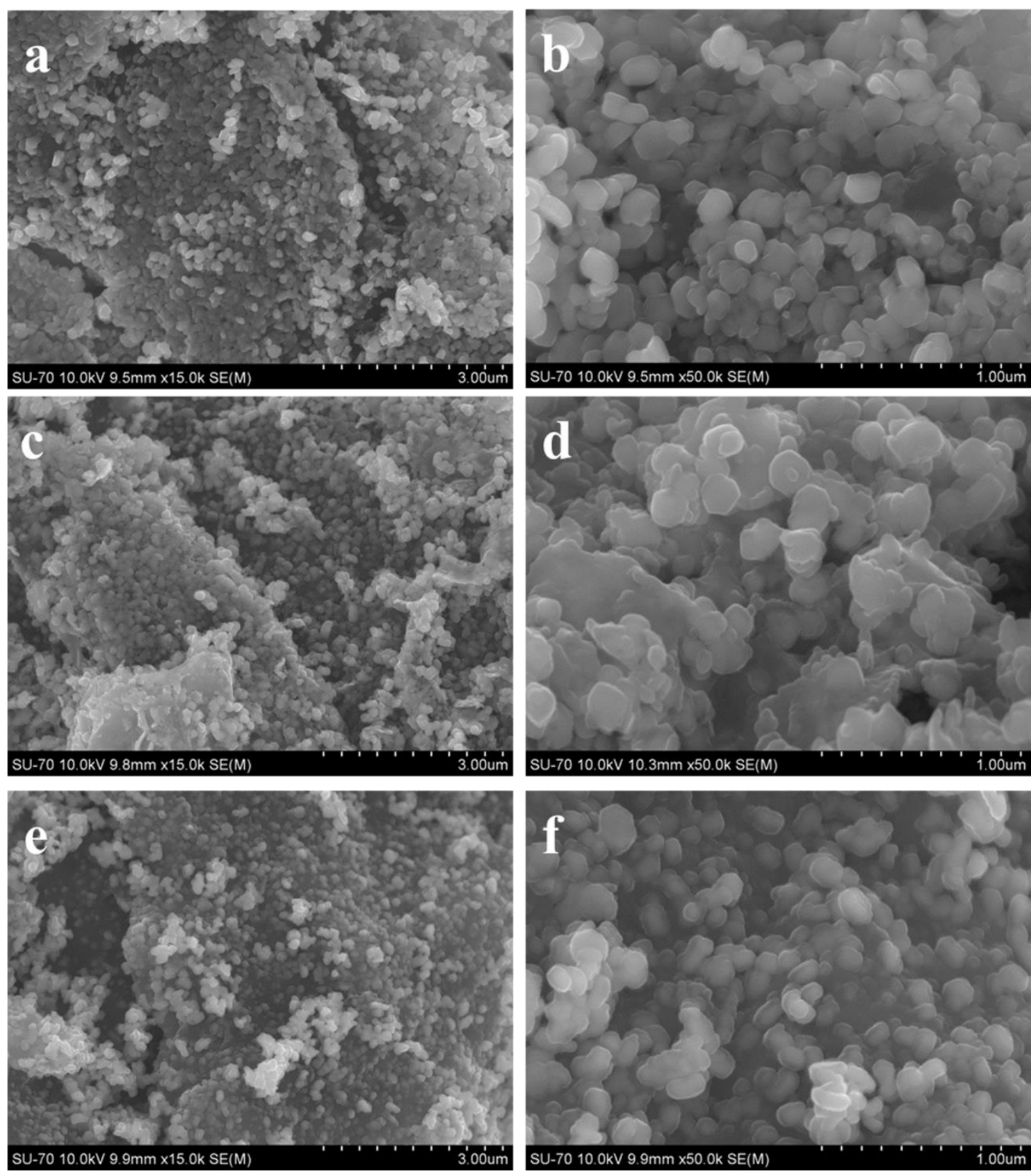

Fig. 2. SEM images of MCC-ZnO2 (a and b; 30 min reaction), MCC-ZnO3 (c and d; $2 \mathrm{~h}$ reaction) and $\mathrm{CH}-\mathrm{ZnO} 4$ (e and f; 30 min reaction) nanocomposites.

The composites MCC-ZnO2 and MCC-ZnO3 were further treated with a solution of alginate. Coating the composites with a layer of alginate (with opposite charge to the ZnO NPs) was tested to evaluate potentially slower Zn release. By SEM analysis of the composites obtained after treatment with alginate (MCC-ZnO2 ALG and MCC-ZnO3 ALG) it was not possible to identify a layer of polymer covering ZnO NPs (Fig. S9, supporting information). However, zeta potential measurements showed an increase of the surface charge of the 
composites obtained after treatment with alginate as compared to the charge of the materials before treatment (Table 2). In the case of MCC-ZnO3 ALG a charge reversal was even observed. This suggested that the negatively charged alginate attached to the composites surface.

\section{Table2}

Zeta potential and $\mathrm{pH}$ of suspensions of $\mathrm{MCC}-\mathrm{ZnO}$ composites treated and non-treated with alginate $^{\text {a }}$

\begin{tabular}{ccc}
\hline Sample & Zeta potential $(\mathbf{m V})$ & $\mathbf{p H}$ \\
\hline $\mathrm{MCC}-\mathrm{ZnO} 2$ & $-18.6 \pm 0.7$ & $7.30 \pm 0.10$ \\
$\mathrm{MCC}-\mathrm{ZnO} 2 \mathrm{ALG}$ & $-32.0 \pm 3.2$ & $7.78 \pm 0.20$ \\
$\mathrm{MCC}-\mathrm{ZnO} 3$ & $+6.0 \pm 2.5$ & $7.36 \pm 0.20$ \\
$\mathrm{MCC}-\mathrm{ZnO} 3 \mathrm{ALG}$ & $-33.9 \pm 2.1$ & $7.75 \pm 0.20$ \\
\hline
\end{tabular}

a Three replicate measurements were performed (values represent mean \pm standard deviation). Both the zeta potential and the $\mathrm{pH}$ of composites treated with alginate were significantly different $(\mathrm{p}<0.05)$ from the non-treated ones.

Entrapment of nutrients and active ingredients onto biopolymers is known to be helpful for controlled release of these compounds. ${ }^{40,48}$ Having this in mind, a composite with high content of $\mathrm{Zn}(64.6 \%)$ was prepared by entrapment of $\mathrm{ZnO}$ NPs in a chitosan gel (G-CH-ZnO5). To prepare the composite a suspension of commercial ZnO NPs was added to a chitosan solution under agitation. According to Vasile et al. ${ }^{40}$ chitosan amino groups interact with ZnO NPs and then the polymer chains wrap around the particles and as a result a chitosan gel is formed with $\mathrm{ZnO}$ NPs trapped inside. In fact, SEM analysis of the milled dried gel clearly showed areas where a film of chitosan was covering ZnO NPs (Fig. 3 a and b) Moreover, TEM images showed that the $\mathrm{ZnO}$ NPs were in fact wrapped by a polymer layer (Fig. $3 \mathrm{c}$ and d). FTIR-ATR analyses also showed that there was a strong interaction between chitosan functional groups and $\mathrm{ZnO}$ surface (Fig. S10, supporting information). Chitosan displays characteristic vibrational bands at $3374 \mathrm{~cm}^{-1}\left(\mathrm{O}-\mathrm{H}\right.$ stretching and $\mathrm{N}-\mathrm{H}$ stretching in $\mathrm{NH}_{2}$ group $), 2868 \mathrm{~cm}^{-1}\left(\mathrm{CH}_{2}, \mathrm{C}-\mathrm{H}\right.$ 
symmetric stretching), $1651 \mathrm{~cm}^{-1}$ (stretching vibration of $\mathrm{C}=\mathrm{O}$ in amide), $1585 \mathrm{~cm}^{-1}\left(\mathrm{NH}_{2}\right.$ bending), $1050-893 \mathrm{~cm}^{-1}$ (vibrations of $\mathrm{C}-\mathrm{O}$ bonds). For composite $\mathrm{G}-\mathrm{CH}-\mathrm{ZnO} 5$ the band at $3374 \mathrm{~cm}^{-1}$ shifted to $3364 \mathrm{~cm}^{-1}$ and became more intense and broad. The peak at $1585 \mathrm{~cm}^{-1}$ correspondent to $\mathrm{NH}_{2}$ bending also became more intense and shifted to lower wavelength (1553 $\mathrm{cm}^{-1}$ ). The shift and the intensity increase of the FTIR peaks was attributed to the interaction of $\mathrm{ZnO}$ with $\mathrm{OH}$ and $\mathrm{NH}_{2}$ groups of chitosan. ${ }^{49} \mathrm{XRD}$ of $\mathrm{G}-\mathrm{CH}-\mathrm{ZnO} 5$ showed the characteristic peaks of $\mathrm{ZnO}$ (wurtzite) as the main crystalline phase in the composite (Fig. S11, supporting information).
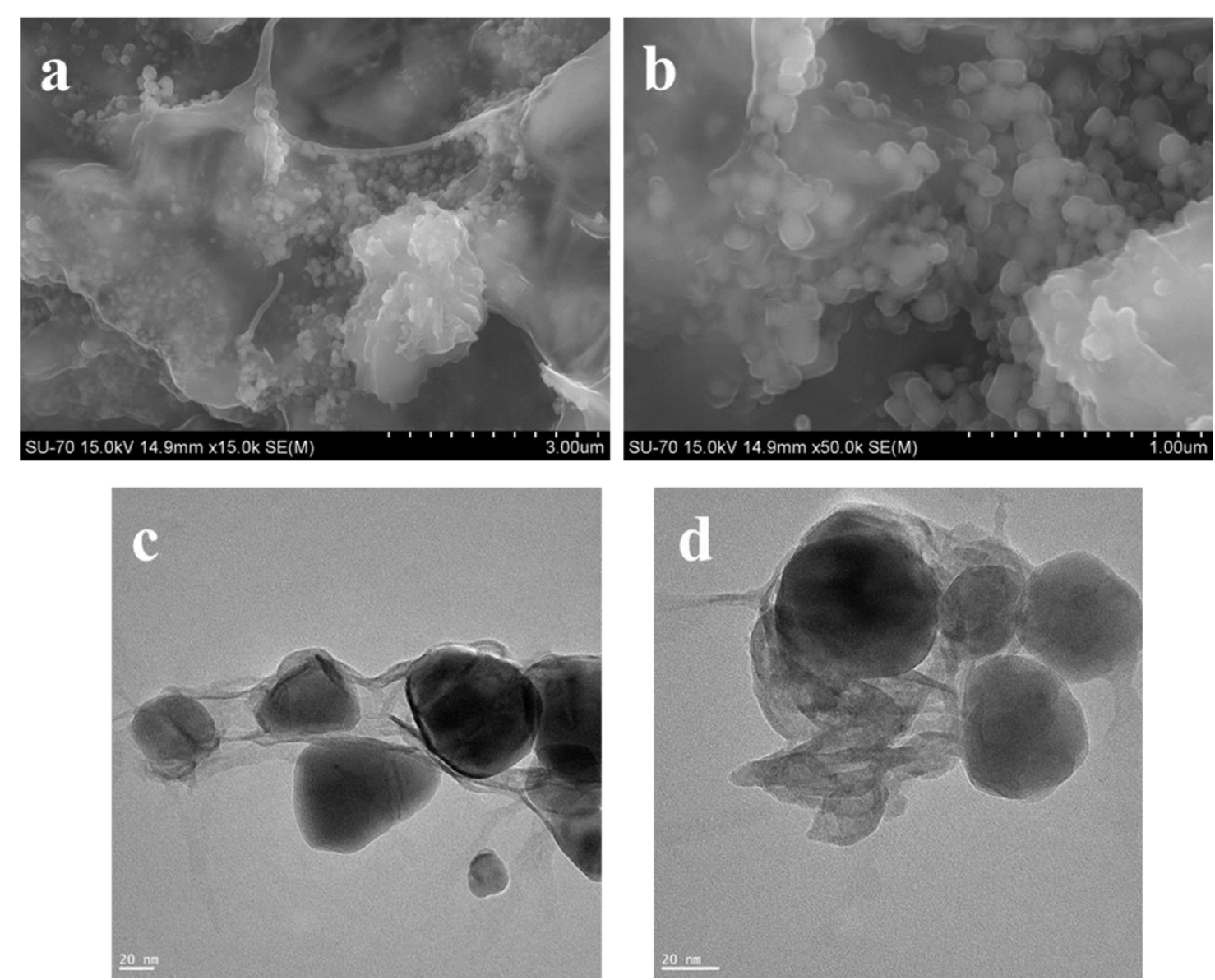

Fig. 3. SEM ( $a$ and $b$ ) and TEM (c and d) images of G-CH-ZnO5.

Other composites were prepared by entrapment of $\mathrm{ZnO}$ NPs inside a gel-like polymeric matrix. Two types of alginate beads containing ZnO NPs were prepared by dropping a suspension of $\mathrm{ZnO}$ NPs onto a solution of $\mathrm{CaCl}_{2}$ (B-ALG6) or $\mathrm{ZnCl}_{2}$ (B-ALG7). The wet beads exhibited spherical shape with a diameter of 1-3 mm (Fig. S12, supporting information). After air drying, the diameter of the beads decreased to about $1 \mathrm{~mm}$; however, most of particles 
maintained the spherical shape. XRD pattern for both alginate beads showed the characteristic peaks of $\mathrm{ZnO}$ wurtzite phase (Fig. S11, supporting information).

$\mathrm{Zn}$ content of B-ALG6 beads was found to be $11.8 \%$ which means that $88 \%$ of the $\mathrm{ZnO}$ NPs that were in the suspension were entrapped by the polymer. SEM analysis of dried BALG6 beads showed a rough surface with some wrinkles and cracks (Fig. 4 a,c). In the highresolution image of B-ALG6 it was possible to observe the $\mathrm{ZnO}$ NPs wrapped by alginate at the bead surface (Fig. 4e). Beads were cut in small pieces allowing the analysis of the interior of the beads. SEM images and Zn EDS mapping of this pieces showed that ZnO NPs were homogeneously distributed in the composite (Fig. S13, supporting information).

For B-ALG7 beads the Zn content (33.5\%) was more than two times higher than the obtained for B-ALG6 and the calculated efficiency of entrapment was higher than $100 \%$. This was due to the fact that $\mathrm{Zn}$ present in the composite was not only derived from ZnO NPs but also from $\mathrm{ZnCl}_{2}$ that acted to cross-link the alginate chains. SEM analyses of the surface of the beads showed not only the $\mathrm{ZnO}$ NPs but also abundant crystal structures (Fig. 4 d,f). It is possible that these crystals are $\mathrm{ZnCl}_{2}$ that precipitated at the surface of the polymers or $\mathrm{ZnO}$ plates obtained by the growth of $\mathrm{ZnO}$ NPs in the presence of $\mathrm{ZnCl}_{2}$. EDS mapping of $\mathrm{Zn}$ on a fragment of B-ALG7 bead revealed that this element is homogeneous distributed on the polymer surface (Fig. S14, supporting information). 

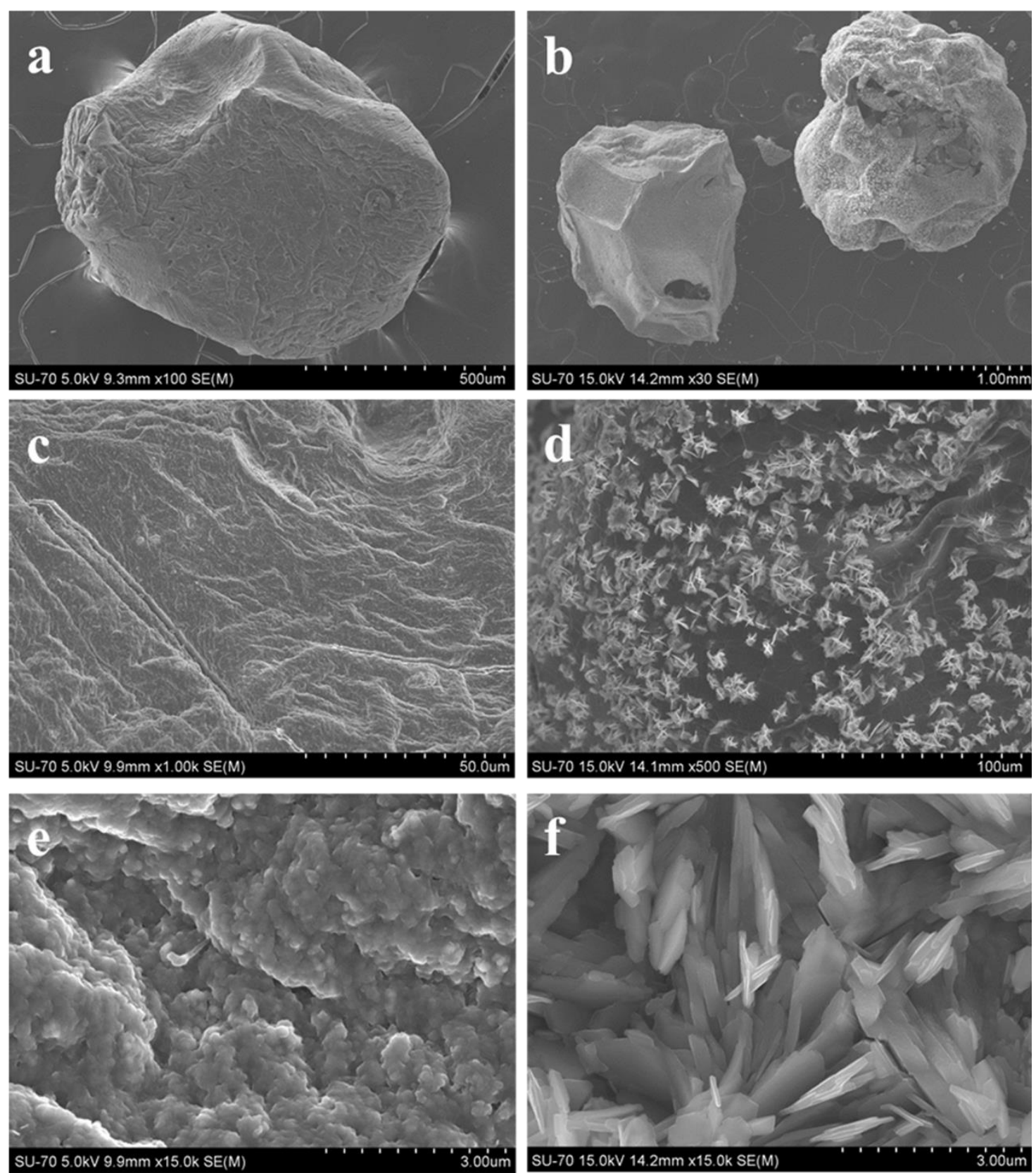

Fig. 4. SEM images of B-ALG6 (a, c and e) and B-ALG7 (b, d and f) nanocomposites.

The ZnO NPs deposition efficiencies for the composites G-CH-ZnO5 and B-ALG6 were 87 and $88 \%$ respectively. These values are similar to the deposition efficiencies of the composites obtained by in situ method (MCC-ZnO2, MCC-ZnO3 and $\mathrm{CH}-\mathrm{ZnO} 4)$ which were between 81 and $94 \%$.

Finally, the $\mathrm{pH}$ of the suspensions of all the prepared composites was measured and values between 6.65 and 7.78 were obtained (Table S1, supporting information). The $\mathrm{pH}$ values of the suspensions of the MCC-ZnO composites treated with alginate (MCC-ZnO2 ALG and MCC- 
$\mathrm{ZnO} 3 \mathrm{ALG})$ were significantly higher $(\mathrm{p}<0.05)$ than the $\mathrm{pH}$ of the suspensions of all remaining materials.

\subsection{Extractability of $\mathrm{Zn}$ from all biopolymer composites in agricultural soils}

The concentrations of $0.01 \mathrm{M} \mathrm{CaCl}_{2}$ extractable $\mathrm{Zn}$ for soil LUFA 2.2 amended with $\mathrm{ZnO}$ composites, $\mathrm{ZnO}$ NPs and $\mathrm{ZnCl}_{2}$ (100 mg of $\mathrm{Zn}$ per $\mathrm{kg}$ of dry soil) after 1 or 7 days of incubation was determined (Fig. 5). For all the materials including $\mathrm{ZnCl}_{2}$, $\mathrm{Zn}$ extractability decreased with time. Lower $\mathrm{Zn}$ extractability over time in soils amended with $\mathrm{ZnCl}_{2}, \mathrm{ZnSO}_{4}$ or $\mathrm{ZnO}$ NPs was also reported by others researchers, ${ }^{50,51}$ and is discussed further below. The extractable $\mathrm{Zn}$ for $\mathrm{ZnO}$ NPs amended soil was always lower than for $\mathrm{ZnCl}_{2}$ amended soil suggesting that $\mathrm{ZnO}$ NPs were not completely dissolved after 7 days of incubation in soil. The $\mathrm{Zn}$ extractability in soil LUFA 2.2 amended with $\mathrm{ZnCl}_{2}$ was significantly higher $(\mathrm{p}<0.05)$ than that of amendments with $\mathrm{ZnO}$ NPs composites.

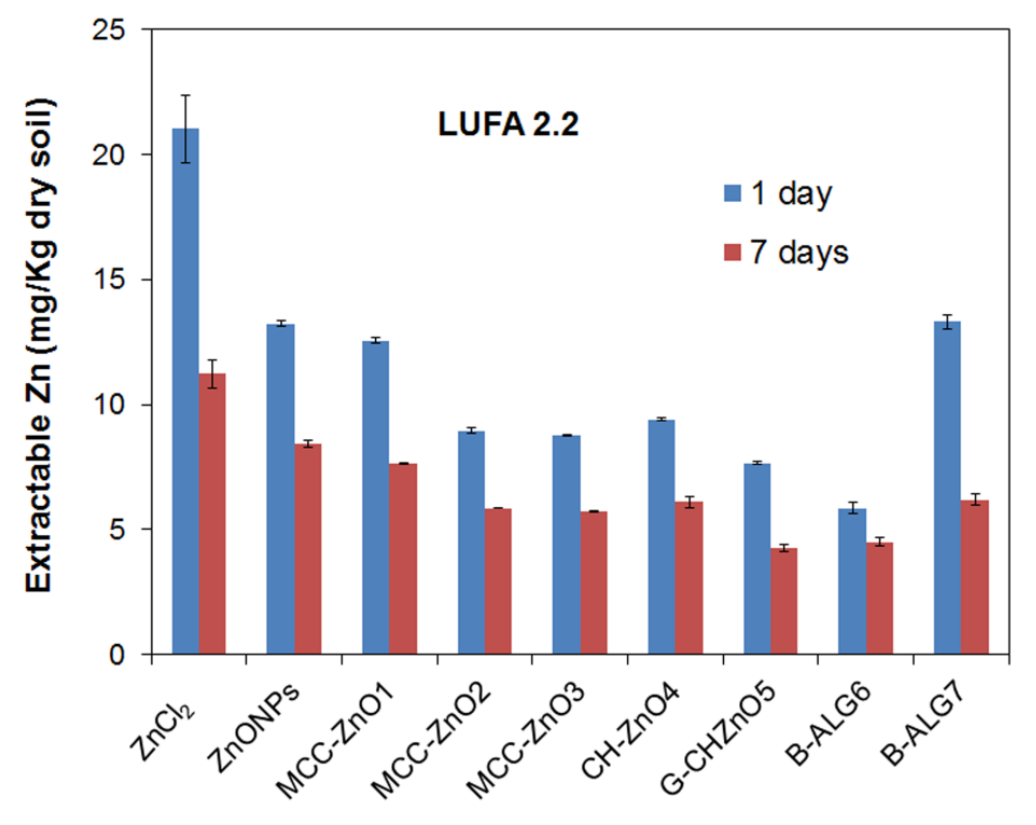

Fig. 5. Extractable Zn from soil LUFA $2.2(\mathrm{pH}=6.3 ; 1.61 \%$ organic carbon) amended with $\mathrm{ZnCl}_{2}, \mathrm{ZnO}$ NPs and $\mathrm{ZnO}$ composites, incubated for 1 or 7 days. Bars represent mean values and error bars represent standard deviation $(\mathrm{n}=3)$.

With the exception of B-ALG7, all amendments with the ZnO NPs composites led to lower Zn extractability from soils than amendments with ZnO NPs alone (Fig. 5 and Table S2). In fact, $\mathrm{Zn}$ extractability decreased between (5.1 and 55.8\%) suggesting a lower release of $\mathrm{Zn}$ on 
soils when ZnO NPs were immobilized in a polymeric matrix. Although slightly lower, MCC$\mathrm{ZnO} 1$ presented $\mathrm{Zn}$ release close to those observed for the $\mathrm{ZnO}$ NPs alone. This was attributed to the fact that the $\mathrm{ZnO}$ NPs on MCC-ZnO1 composite were mostly deposited onto the surface of MCC fibers and were only attached by electrostatic forces. When in the soil, the ZnO NPs could easily detach making the material behave similarly to that observed for non-immobilized $\mathrm{ZnO}$ NPs. Composites produced by in situ synthesis (MCC-ZnO2, MCC-ZnO3 and $\mathrm{CH}-\mathrm{ZnO} 4$ ) presented a lower $\mathrm{Zn}$ release (extractability was 1.2-1.4 lower) compared with MCC-ZnO1. In this case, is possible that most of the $\mathrm{ZnO}$ NPs were attached to the polymer by chemical bonds or trapped between polymeric fibbers making more difficult the $\mathrm{Zn}$ release. However, the release of $\mathrm{Zn}$ was similar for $\mathrm{MCC}-\mathrm{ZnO} 2, \mathrm{MCC}-\mathrm{ZnO} 3$ and $\mathrm{CH}-\mathrm{ZnO} 4$ showing that the type of polymeric substrate and size of the ZnO NPs had no decisive role on the $\mathrm{Zn}$ release for the materials prepared by in situ method.

MCC-ZnO2 ALG and MCC-ZnO3 ALG (prepared by the treatment of MCC-ZnO composites with alginate) showed $\mathrm{Zn}$ release levels similar to the untreated composites (Table $\mathrm{S} 2)$; however, it is possible to see a trend of lower release (2-10\% less) for the treated materials.

The materials showing the slowest $\mathrm{Zn}$ release were those prepared by entrapment of $\mathrm{ZnO}$ NPs in a gel structure (G-CHZnO5 and B-ALG6). Clearly, the extractability of Zn from soil LUFA 2.2 amended with B-ALG6 alginate beads was two and three times lower than the extractability of the soil amended with $\mathrm{ZnO}$ NPs and $\mathrm{ZnCl}_{2}$ respectively. Although the $\mathrm{Zn}$ extractability for G-CHZnO5 in the end of day 1 was higher than for B-ALG6 it became similar after 7 days of incubation. For these materials, water molecules need to diffuse through pores and channels of the polymeric gel to get in contact with ZnO NPs and to dissolve them. After that, the ionic $\mathrm{Zn}$ must diffuse throughout of the gel to be released onto soil pore water. This process hinders a rapid dissolution of $\mathrm{ZnO}$ NPs.

It should be mentioned that B-ALG7 alginate beads that were produced using $\mathrm{ZnCl}_{2}$ as crosslinking agent instead of $\mathrm{CaCl}_{2}$ presented almost the same $\mathrm{Zn}$ release after 1 day of incubation as the amendment with ZnO NPs alone. This could be explained by the fact that at least half of the $\mathrm{Zn}$ present in the composite was not in $\mathrm{ZnO}$ NPs form. In fact, part of the zinc was founded at alginate chains (as crosslinking agent) or adsorbed at the surface of the polymer.

It was clear that the fraction of extractable Zn was significantly higher in soil LUFA 2.1 (44-88 \% of added Zn content) then in soil LUFA 2.2 (5-21\%) for all the materials, including $\mathrm{ZnCl}_{2}$ (Fig. 6 and Table S3). This was attributed to the lower $\mathrm{pH}$ (5.2) and lower organic matter content $(0.71 \%$ organic carbon) of soil LUFA 2.1 compared with LUFA $2.2(\mathrm{pH}=6.3 ; 1.61 \%$ organic carbon). Other authors also reported that soils with low $\mathrm{pH}$ and low organic matter 
content show a higher lability of $\mathrm{Zn} .{ }^{52,53}$ The Zn extractability in soil LUFA 2.1 amended with $\mathrm{ZnCl}_{2}$ was significantly higher $(\mathrm{p}<0.05)$ than that of $\mathrm{ZnO}$ NPs composites and of $\mathrm{ZnO}$ NPs alone.

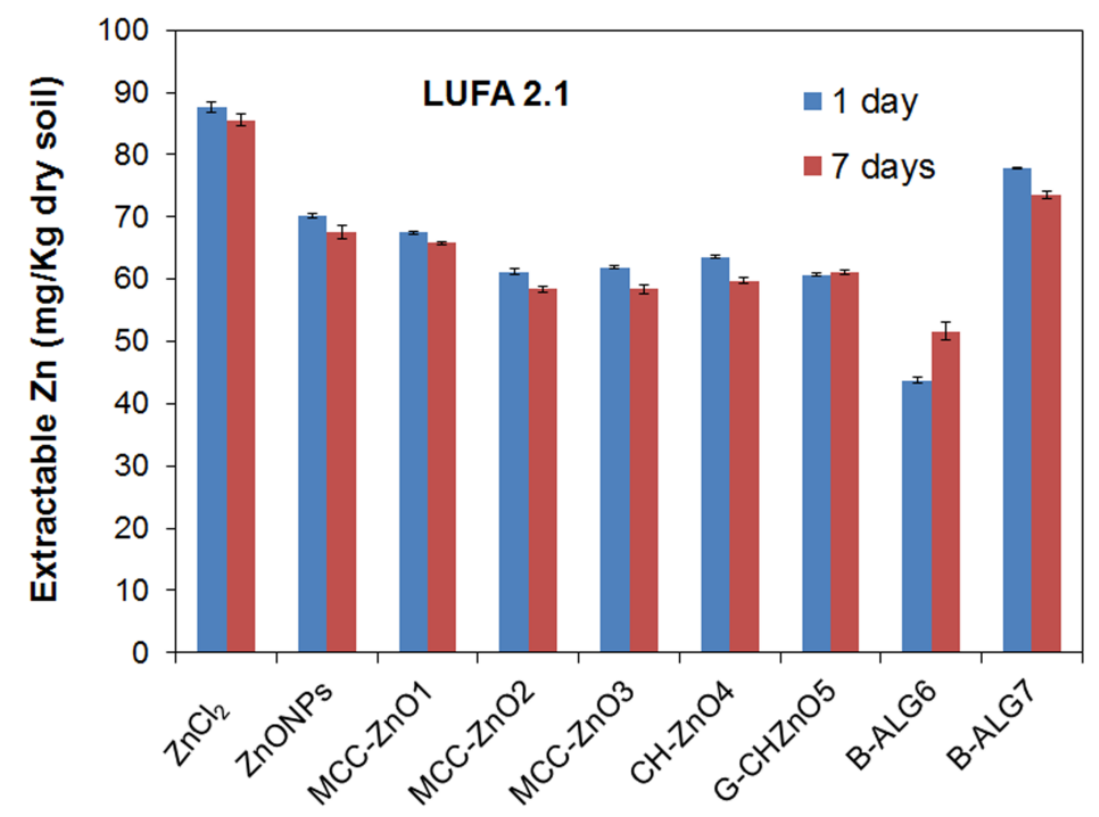

Fig. 6. Extractable $\mathrm{Zn}$ from soil LUFA $2.1(\mathrm{pH}=5.2 ; 0.71 \%$ organic carbon) amended with $\mathrm{ZnCl}_{2}, \mathrm{ZnO}$ NPs and $\mathrm{ZnO}$ composites, incubated for 1 or 7 days. Bars represent mean values and error bars represent standard deviation $(n=3)$.

For both LUFA 2.2 and LUFA 2.1 soils all the composites presented lower Zn extractability compared with ZnO NPs, with the exception of B-ALG7. However, the differences in $\mathrm{Zn}$ release between the different composites were clearly smaller for soil LUFA 2.1. This shows that the percentage and rate of $\mathrm{Zn}$ release from the composites is not only determined by the type of attachment of the ZnO NPs to the polymer but also by soil properties, particularly $\mathrm{pH}$ and organic carbon content. It was clear that the alginate beads containing $\mathrm{ZnO}$ NPs prepared by crosslinking with $\mathrm{CaCl}_{2}$ (B-ALG6) were the materials that presented the lower $\mathrm{Zn}$ release in both soils. 


\subsection{Extractability of $\mathrm{Zn}$ from agricultural soils dosed with ZnONPs/alginate beads composites along 30 days}

A soil test with a longer incubation time (30 days) and more data points (day 1, 4, 7, 15 and 30) was performed to further evaluate the Zn release behaviour from B-ALG6 along time. The behaviour of B-ALG6 was compared with that observed for $\mathrm{ZnCl}_{2}$ in the same period of time.

The concentration of $\mathrm{CaCl}_{2}$ extractable $\mathrm{Zn}$ from soils $\mathrm{DE}(\mathrm{pH}=6.9)$ and $\mathrm{VV}(\mathrm{pH}=7)$ amended with $\mathrm{ZnCl}_{2}$ was between $0.736 \mathrm{mg} / \mathrm{kg}$ (day 1) and $0.09 \mathrm{mg} / \mathrm{kg}$ (day 30). For B-ALG6 the concentration of extractable $\mathrm{Zn}$ was below the detection limit of ICP-MS analysis from day 1 to day 30 (Table S4, supporting information). This suggests that these materials may not be efficient for controlled release of $\mathrm{Zn}$ in neutral/alkaline soils.

The concentrations of $0.01 \mathrm{M} \mathrm{CaCl}_{2}$ extractable $\mathrm{Zn}$ for soil LUFA 2.2 amended with BALG6 and $\mathrm{ZnCl}_{2}$ over 30 days are shown in Fig. 7 (a). The materials exhibited distinct behaviour in relation to extractable $\mathrm{Zn}$. In the $\mathrm{ZnCl}_{2}$ amended soil, the extractable $\mathrm{Zn}$ was high in the first day and then showed a fast decrease with time. A decrease of $60 \%$ in the extractable Zn was observed from day 1 to day 15 of incubation in soil. After 15 days of incubation the extractable $\mathrm{Zn}$ further decreased but at a slower rate. This behaviour could be a result of an initial rehydration of the soil, followed by ionic $\mathrm{Zn}$ micropore diffusion, and further complexation in soil by organic matter (SOM) or incorporation/precipitation of $\mathrm{Zn}$ in/onto stable oxide mineral phases. ${ }^{24,25}$ 

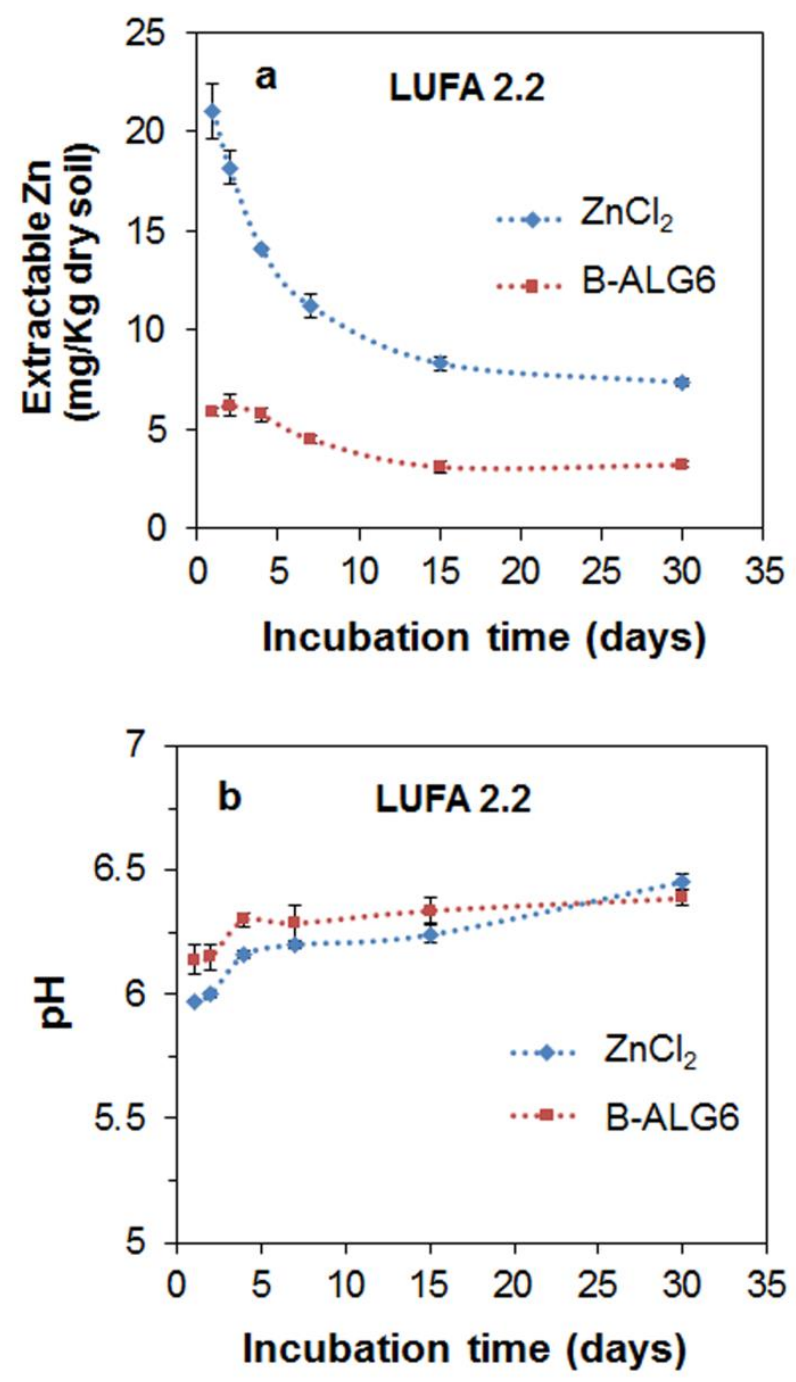

Fig. 7. (a) Extractable $\mathrm{Zn}$ from soil LUFA 2.2. amended with $\mathrm{ZnCl}_{2}$ and B-ALG6 as function of time (b) $\mathrm{pH}$ of the extracts. To better visualize the trend of the results the points in the graphics were joined with dotted lines. Error bars represent standard deviation of the mean $(\mathrm{n}=3)$.

In the case of B-ALG6 amended soil there is a small increase of Zn extractability from day 1 to day 2. This was followed by a period of slow decrease of $\mathrm{Zn}$ extractability until a plateau is reached in the end of 15 days. The increase in $\mathrm{Zn}$ extractability in the first two days suggested that the ZnO NPs were becoming more extractable as a result of acid-promoted dissolution of $\mathrm{ZnO}$ NPs (eq. (1)).

$$
\mathrm{ZnO}(\mathrm{s})+2 \mathrm{H}^{+}(\mathrm{aq}) \leftrightarrow \mathrm{Zn}^{2+}(\mathrm{aq})+\mathrm{H}_{2} \mathrm{O}(\mathrm{l})
$$

At the end of 30 days of incubation after soil dosing, the extractable $\mathrm{Zn}$ for B-ALG6 amended soil was still lower than for $\mathrm{ZnCl}_{2}$ amended soil suggesting that $\mathrm{ZnO}$ NPs dissolution was not complete in this period of time. It was also possible to observe that the $\mathrm{pH}$ of the extracts 
of B-ALG6 amended soil in the first 15 days was higher than for soil amended with $\mathrm{ZnCl}_{2}(\mathrm{Fig}$. 7b). This can be also attributed to the acidic dissolution of $\mathrm{ZnO}$ NPs, as described by eq.(1).

Similar trends were observed for LUFA 2.1 amended soils (Fig. 8 a). In the soil amended with $\mathrm{ZnCl}_{2}, 88 \%$ of the $\mathrm{Zn}$ added to the soil was extractable in the first day, while in the soil amended with B-ALG6 only $44 \%$ was extractable. The $\mathrm{ZnCl}_{2}$ amended soils showed a decrease in the extractable Zn over 15 days, whereas the B-ALG6 amended soils presented a small increase in the extractable $\mathrm{Zn}$ in the first 7 days and after that the concentration of extractable $\mathrm{Zn}$ was almost constant. For soil LUFA 2.1 amended with B-ALG6 the period of time where an increase of $\mathrm{Zn}$ extractability is registered is higher (7 days, against 2 days in soil LUFA 2.2). This was attributed to the more acidic nature of this soil ( $\mathrm{pH}$ of 5.2) that can promote faster dissolution of ZnO NPs (eq. (1)).
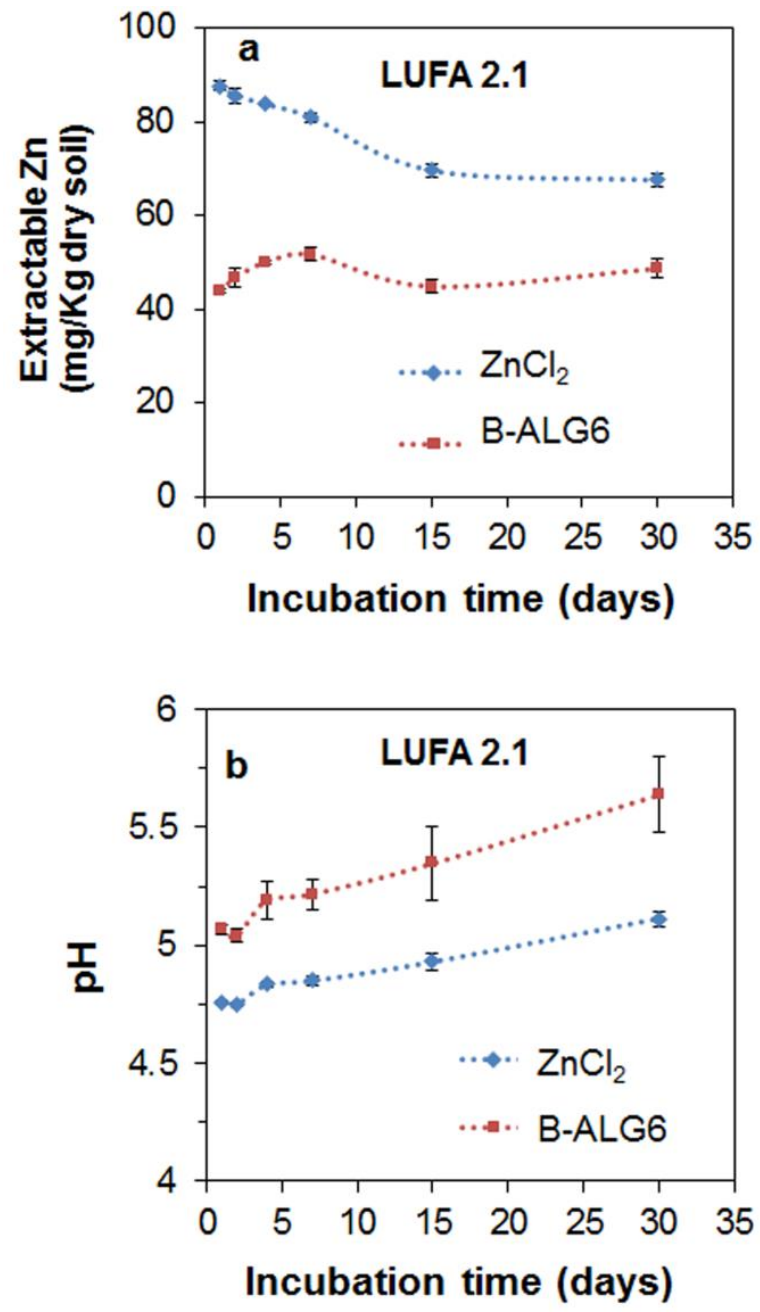

Fig. 8. (a) Extractable $\mathrm{Zn}$ from soil LUFA 2.1. amended with $\mathrm{ZnCl}_{2}$ and B-ALG6 as function of time (b) $\mathrm{pH}$ of the extracts. To better visualize the trend of the results the points in the graphics were joined with dotted lines. Error bars represent standard deviation of the mean $(n=3)$. 
As clearly shown in Figures 7 and 8, difference between the $\mathrm{pH}$ values of the extracts of BALG6 amended soil and the extracts of $\mathrm{ZnCl}_{2}$ amended soil was higher in soil LUFA 2.1 than in soil LUFA 2.2. This could be related with the degradation of the polymeric matrix in this soil with the formation of products with alkaline character. Kanakaraju et al. ${ }^{54}$ also reported an increase of the $\mathrm{pH}$ of a solution containing alginate beads with time and the degradation of alginate was pointed out as one of the possible causes for the $\mathrm{pH}$ rise.

\subsection{Controlled release of $\mathrm{Zn}$ from $\mathrm{ZnO}$ NPs/alginate beads for Maize fertilization in acidic soil}

To investigate the potential of $\mathrm{ZnO}$ NPs alginate beads (B-ALG6) to be use in Zn-deficient acidic soil as a $\mathrm{Zn}$ source for maize, the growth of maize was assessed in LUFA 2.1 supplied with different $\mathrm{Zn}$ sources ( $\mathrm{ZnCl}_{2}, \mathrm{ZnO}$ NPs or B-ALG6), at 30 or $100 \mathrm{mg}$ of $\mathrm{Zn}$ per kg of dry soil. Controls (soil amended with ultrapure water, or with the equivalent mass of alginate as what was amended in the B-ALG6 treatment) were also run in parallel.

As described for the extractable $\mathrm{Zn}$ in soils incubated without plants, adding $\mathrm{Zn}$ to LUFA 2.1 increased the $\mathrm{Zn}$ concentration in the pore water for all days in comparison to the non-zinc controls (see Fig. 9 a and Table S5). While this increase was high at day 2, it stabilized at day 29 as it was 2-4 times higher for all the $30 \mathrm{mg} / \mathrm{Kg}$ amendments, and 9-17 time higher for the $100 \mathrm{mg} / \mathrm{Kg}$ amendments (Table S5). The zinc concentrations in the pore water decreased from day 2 to day 29 for all conditions. While this decrease was the highest for $\mathrm{ZnCl}_{2}$ treatments ( $94 \%$ and $91 \%$ of decrease for the $30 \mathrm{ppm}$ and $100 \mathrm{ppm}$ amendment, respectively), the B-ALG6 treatment was the one that showed the lowest decrease (72 and 79\% of decrease for the $30 \mathrm{ppm}$ and $100 \mathrm{ppm}$ treatment, respectively), indicating that the loss of $\mathrm{Zn}$ by leaching in soil for that treatment was lowered (see Table S5). This decrease in Zn pore water concentrations over time seems to be driven by its $\mathrm{pH}$ increase (Figure 9a) as these traits significantly correlates together (Figure S15a).

The $\mathrm{CaCl}_{2}$ extractable $\mathrm{Zn}$ concentrations in the bulk soil (far away from the main root systems) follow similar trends, with higher $\mathrm{Zn}$ amendment increasing the extractable $\mathrm{Zn}$, following the trend $\mathrm{ZnCl}_{2}=\mathrm{ZnO}$ NPs $>$ B-ALG6 (Figure 9b). 


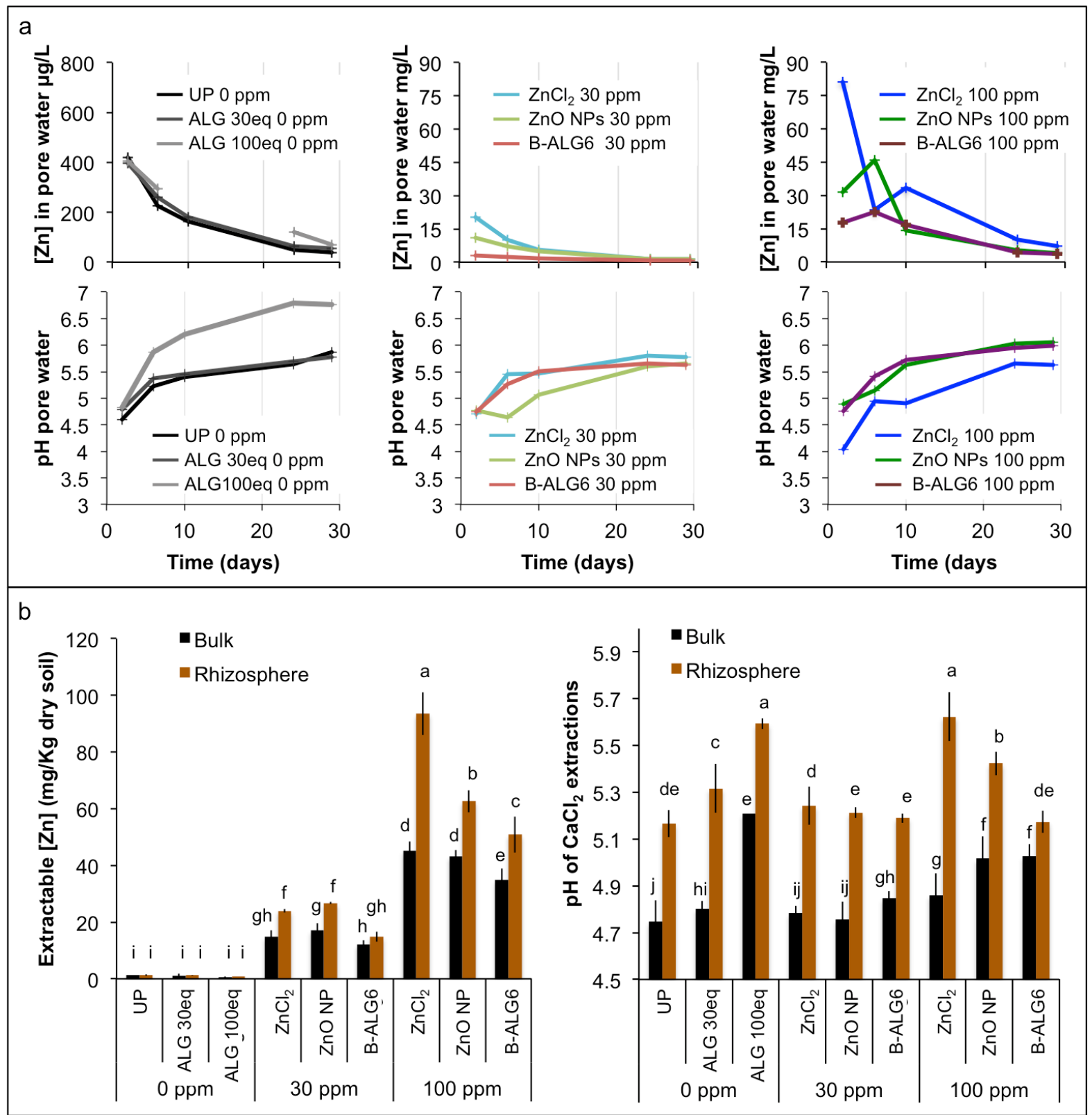

Fig. 9. (a) Zinc concentration in LUFA 2.1 pore water along with its $\mathrm{pH}$ over the time of maize growth for 29 days, and (b) extractable $\mathrm{Zn}$ at day 29 in both the bulk or rhizosphere soil along with its pH. UP is the control. ALG 30eq and ALG 100eq are the LUFA 2.1 soil dosed with equivalent ALG doses as the composite treatments. $\mathrm{Zn}$ was amended as $\mathrm{ZnCl}_{2}, \mathrm{ZnO} \mathrm{NPs}$, BALG6 at 30 or $100 \mathrm{mg}$ of zinc per Kg of dry soil. Different letters indicate of different means (ANOVA, $\mathrm{p}<0.05$ ) 
These differences among treatments are even clearer in the rhizosphere soil, where all the overall extractable $\mathrm{Zn}$ concentrations are higher than in the bulk soils. This highlights the great influence of the roots exudation on the Zn bioavailability in the rhizosphere. It is noteworthy that in the rhizosphere, all of the $\mathrm{pH}\left(1: 10\right.$ soil:0.01 $\left.\mathrm{M} \mathrm{CaCl}_{2}\right)$ were also significantly higher than in the bulk soils (Figure $9 \mathrm{~b}$ ), which was surprising giving the higher extractable $\mathrm{Zn}$ concentrations. Indeed, while extractable $\mathrm{Zn}$ concentrations were negatively correlated with the $\mathrm{pH}$ in the bulk soil, this correlation was positive in the rhizosphere soil (Figure S15b). This indicates that plants and their microbiome can release compounds that increase $\mathrm{Zn}$ bioavailability in a non-pH dependant manner in the rhizosphere, as exo-polysaccharides, organic matter, organic acids and/or chelators. ${ }^{55}$ Similar conclusions have been made while studying $\mathrm{Cu}$ bioavailability in the rhizosphere. ${ }^{56}$ This underlies the need of considering the fate of (micro)nutrients in the rhizosphere (fate at the root-soil interface), while studying soil physical-chemical parameters influencing (micro)nutrients bioavailability. Reactions in the rhizosphere, will likely be different than in the bulk soil, changing the predictions ${ }^{57}$ of micronutrient bioavailability and biogeochemical cycling in the latter when plants are present.

The highest $\mathrm{pH}(>5.5)$ observed for $\mathrm{ZnCl}_{2}$ and $\mathrm{ZnO}$ NPs $100 \mathrm{ppm}$ could be a response of the plant to a (too) high bioavailable zinc concentration in its roots vicinity, ${ }^{55}$ that induce toxic impacts on the plant growth. Indeed, the dry biomass of the maize plant grown on these soils seems to validate this hypothesis. Maize growing on the soils presenting the highest extractable $\mathrm{Zn}\left(\mathrm{ZnCl}_{2}\right.$ and $\mathrm{ZnO}$ NPs dosed at $\left.100 \mathrm{mg} / \mathrm{Kg}\right)$ produced less biomass than the control without $\mathrm{Zn}$ addition (Figure 10). The smaller plants and biomass observed for the alginate control could be due to an increase of $\mathrm{pH}$ induced by the alginate presence that may reduce bioavailability of other micronutrients. These results illustrate well how too low of a micronutrient bioavailability impair plant growth, while too much of it induce toxic impacts.

Of all the treatments, B-ALG6 100 ppm was the only one showing an increase in plant biomass and density, slightly improving the plant growth. It is noteworthy that the fact that this increase was not statistically significant was likely because the experiment was stopped at 29 days, while Zn deficiency effects on the biomass appears in latter stages of the plant growth. This could explain why significant differences in biomass where not observed in the B-ALG6 treated soil in comparison with the control soil, while the conditions for $\mathrm{Zn}$ deficiencies in LUFA 2.1 were met (Zn pore water $<0.5 \mathrm{mg} / \mathrm{L}^{14}$ and $<1 \mathrm{ppm}$ of DTPA-extractable $\mathrm{Zn}$ ). ${ }^{23}$ However, some early signs of Zn deficiency (chlorisis and yellow margins) were observed on the maize leaves growing on LUFA 2.1 soil (see Figure S16), that did not appear when grown on the zinc-amended soils. Signs of toxicity were observed for the $\mathrm{ZnO} \mathrm{NPs}$ and $\mathrm{ZnCl}_{2}$ 
treatments at $100 \mathrm{mg} / \mathrm{Kg}$ of concentration (see Figure S16). From all the treatments, B-ALG6 dosed at $100 \mathrm{mg}$ of $\mathrm{Zn}$ per $\mathrm{Kg}$ of soil was the only treatment that slightly improved plant growth, while not presenting any signs of Zn deficiencies nor metallic toxicity.

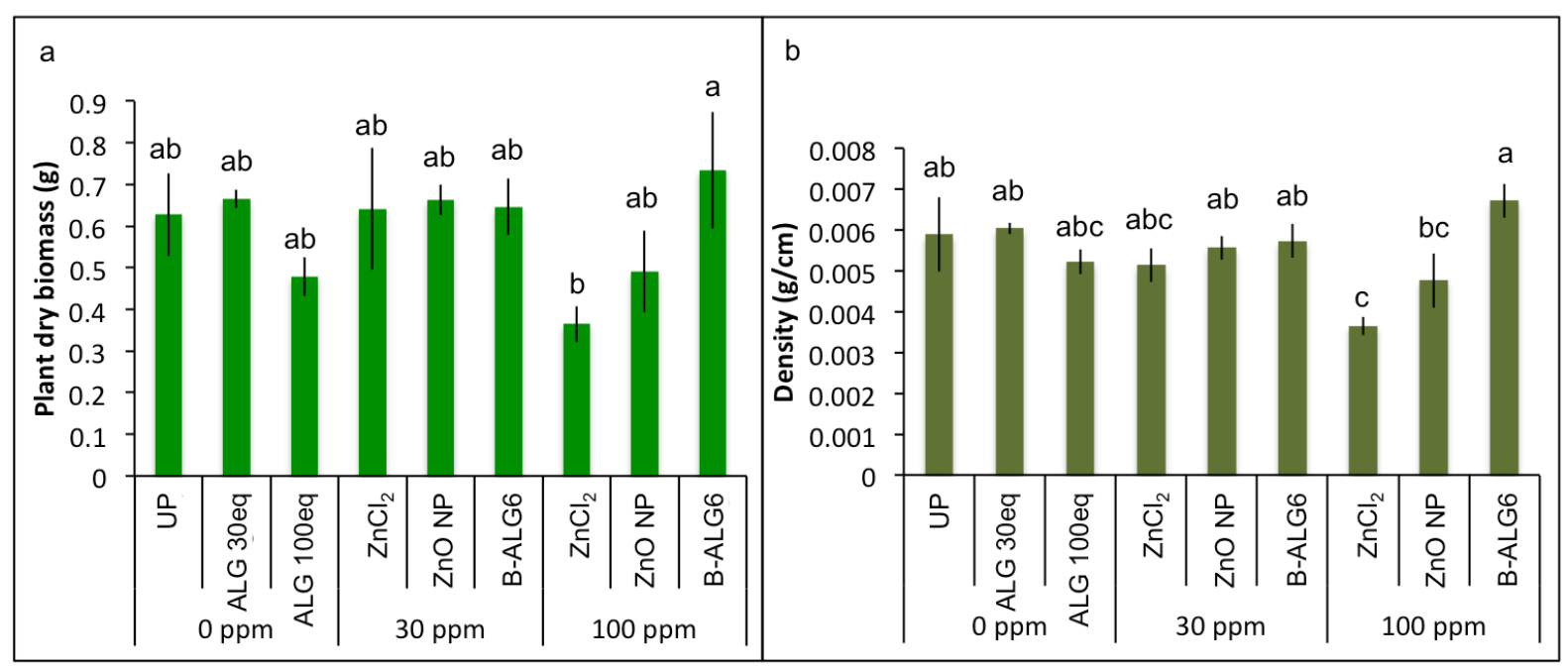

Fig. 10. Maize after 29 days of growth in LUFA 2.1 amended with different treatments and (a) their biomass or (b) their density (shoot biomass normalized by the leaves length). Different letters indicate of different means (ANOVA, $\mathrm{p}<0.05$ )

\section{CONCLUSIONS}

These results illustrate how precise the strategies for fertilisation have to be to meet plants (micro)nutrients needs, while avoiding waste generation, water contamination, metal leaching in the environment, and toxic effects on soil organisms. This study demonstrates that the immobilization of $\mathrm{ZnO}$ NPs onto natural polymers is a way to produce materials that release $\mathrm{Zn}$ in soils in a controlled manner. The composites of biopolymers and $\mathrm{ZnO}$ NPs produced here showed lower $\mathrm{Zn}$ release in acidic soil than $\mathrm{ZnCl}_{2}$ or $\mathrm{ZnO}$ NPs alone, with $\mathrm{Zn}$ release which was soils- and polymer- type dependent. Our results suggest that ZnO NPs immobilized onto alginate beads (prepared by crosslinking with $\mathrm{CaCl}_{2}$ ) can be used for controlled release of $\mathrm{Zn}$ in agricultural soils. This $\mathrm{ZnO}$ NPs/alginate beads could thus meet the $\mathrm{Zn}$ needs of maize plant on the acidic soil LUFA 2.1. In comparison, conventional salts of $\mathrm{ZnCl}_{2}$ have to be added in the soil in high quantities to meet the plant needs after its leaching in the soil, which can induce toxic responses at the earlier stage of the plant growth, and represent a large waste of materials. 
This study demonstrates that fertilisers that can slowly release micronutrient in a controlled manner, as the one presented here, can supply enough $\mathrm{Zn}$ for a plant to grow well, while reducing the $\mathrm{Zn}$ losses. Because of this long-term release, this kind of material could be applied once in the soil and be reused for several crop cycling.

Further studies of $\mathrm{Zn}$ release from these types of materials should be performed for longer times to better understand the fate of these materials in the bulk soil in comparison to the soil of the rhizosphere, to ensure the safety of materials for use in agri-food production. Scalability and cost are also important parameters that must be considered when analysing the viability of such new fertilizers from a commercial point of view.

\section{ASSOCIATED CONTENT}

\section{Supporting Information}

SEM and TEM images and particle size distribution histogram for commercial ZnO NPs ; XRD pattern for $\mathrm{ZnO}$ NPs and for $\mathrm{ZnO}$ composites; UV-visible spectra of $\mathrm{ZnO}$ NPs and $\mathrm{ZnO}$ composites; EDS spectrum of MCC-ZnO1; TEM image of MCC-ZnO2; SEM images of MCCZnO2 ALG and MCC-ZnO3 ALG; FTIR-ATR spectra of G-CH-ZnO5; Photographs of alginate beads and SEM images of the interior of the beads; $\mathrm{pH}$ values of suspensions of all the materials; Extractable $\mathrm{Zn}$ from soils DE and VV amended with B-ALG6 or $\mathrm{ZnCl}_{2}$ (30 days incubation test); Photographs showing $\mathrm{Zn}$ deficiencies in maize grow; Correlations between $\mathrm{Zn}$ concentration in pore water or bulk soil or rhizosphere soil and $\mathrm{pH}$; Decrease of $\mathrm{Zn}$ concentration in soil pore water between day 2 and day 29 for the different treatments.

\section{ACKNOWLEDGMENTS}

Thanks are due for the financial support to CESAM (UID/AMB/50017 - POCI-01-0145FEDER-007638), to Portuguese FCT/MCTES through national funds (PIDDAC), and the cofunding by the FEDER, within the PT2020 Partnership Agreement and Compete 2020, under project NanoFertil (references: POCI-01-0145-FEDER-016749 and PTDC/AGRPRO/6262/2014). S. M. Rodrigues also acknowledges the financial support from FCT (Project IF/01637/2013). Tito Trindade and Natércia Martins thank the CICECO-Aveiro Institute of Materials (Ref. FCT UID /CTM /50011/2019), financed by national funds through the FCT/MEC and when appropriate co-financed by FEDER under the PT2020 Partnership Agreement. Natércia Martins is funded by National funds (OE), through FCT- Fundação para a Ciência e Tecnologia, I.P., in the scope of the framework contract foreseen in the numbers 4 , 
5 and 6 of the article 23, of the Decree-Law 57/2016, of August 29, changed by the law 57/2017, of July 19.

\section{REFERENCES}

(1) Feiner, L. F. Nanoelectronics: Crossing Boundaries and Borders. Nat. Nanotechnol. 2006, 1, 91-92.

(2) Bera, R.; Dutta, A.; Kundu, S.; Polshettiwar, V.; Patra, A. Design of a CdS/CdSe Heterostructure for Efficient $\mathrm{H} 2$ Generation and Photovoltaic Applications. J. Phys. Chem. C 2018, 122, 12158-12167.

(3) Fonseca-Santos, B.; Gremião, M. P. D.; Chorilli, M. Nanotechnology-Based Drug Delivery Systems for the Treatment of Alzheimer's Disease. Int. J. Nanomedicine. 2015, 10, 4981-5003.

(4) Jiang, B.; Lian, L.; Xing, Y.; Zhang, N.; Chen, Y.; Lu, P.; Zhang, D. Advances of Magnetic Nanoparticles in Environmental Application: Environmental Remediation and (Bio)Sensors as Case Studies. Environ. Sci. Pollut. Res. 2018, 25, 30863-30879.

(5) Rodrigues, S. M.; Demokritou, P.; Dokoozlian, N.; Hendren, C. O.; Karn, B.; Mauter, M. S.; Sadik, O. A.; Safarpour, M.; Unrine, J. M.; Viers, J.; et al. Nanotechnology for Sustainable Food Production: Promising Opportunities and Scientific Challenges. Environ. Sci.: Nano. 2017, 4, 767-781.

(6) Khot, L. R.; Sankaran, S.; Maja, J. M.; Ehsani, R.; Schuster, E. W. Applications of Nanomaterials in Agricultural Production and Crop Protection: A Review. Crop Prot. 2012, 35, 64-70.

(7) Baker, S.; Volova, T.; Prudnikova, S. V.; Satish, S.; Prasad M.N., N. Nanoagroparticles Emerging Trends and Future Prospect in Modern Agriculture System. Environ. Toxicol. Pharmacol. 2017, 53, 10-17.

(8) Kah, M.; Kookana, R. S.; Gogos, A.; Bucheli, T. D. A Critical Evaluation of Nanopesticides and Nanofertilizers Against Their Conventional Analogues. Nat. Nanotechnol. 2018, 13, 677-684.

(9) Kumaraswamy, R. V.; Kumari, S.; Choudhary, R. C.; Pal, A.; Raliya, R.; Biswas, P.; Saharan, V. Engineered Chitosan Based Nanomaterials: Bioactivities, Mechanisms and Perspectives in Plant Protection and Growth. Int. J. Biol. Macromol. 2018, 113, 494506.

(10) Raliya, R.; Saharan, V.; Dimkpa, C.; Biswas, P. Nanofertilizer for Precision and Sustainable Agriculture: Current State and Future Perspectives. J. Agric. Food Chem. 2018, 66, 6487-6503.

(11) Servin, A. D.; White, J. C. Nanotechnology in Agriculture: Next Steps for Understanding Engineered Nanoparticle Exposure and Risk. NanoImpact 2016, 1, 9 12.

(12) Savassa, S. M.; Duran, N. M.; Rodrigues, E. S.; de Almeida, E.; van Gestel, C. A. M.; Bompadre, T. F. V.; P. de Carvalho, H. W. Effects of ZnO Nanoparticles on Phaseolus Vulgaris Germination and Seedling Development Determined by X-Ray Spectroscopy . ACS Appl. Nano Mater. 2018, 1, 6414-6426.

(13) Dimkpa, C. O.; Bindraban, P. S. Nanofertilizers: New Products for the Industry? J. Agric. Food Chem. 2018, 66, 6462-6473.

(14) Liu, R.; Lal, R. Potentials of Engineered Nanoparticles as Fertilizers for Increasing Agronomic Productions. Sci. Total Environ. 2015, 514, 131-139.

(15) Chhipa, H. Nanofertilizers and Nanopesticides for Agriculture. Environ. Chem. Lett. 2017, 15, 15-22.

(16) Achari, G. A.; Kowshik, M. Recent Developments on Nanotechnology in Agriculture: 
(26) Cakmak, I. Enrichment of Cereal Grains with Zinc: Agronomic or Genetic Biofortification? Plant and Soil. 2008, 302, 1-17.

(27) Alloway, B. J. Soil Factors Associated with Zinc Deficiency in Crops and Humans. Environ. Geochem. Health 2009, 31, 537-548.

(28) Zhao, A. Q.; Tian, X. H.; Chen, Y. L.; Li, S. Application of ZnSO4 or Zn-EDTA Fertilizer to a Calcareous Soil: Zn Diffusion in Soil and Its Uptake by Wheat Plants. $J$. Sci. Food Agric. 2016, 96, 1484-1491.

(29) Lin, D.; Xing, B. Phytotoxicity of Nanoparticles: Inhibition of Seed Germination and Root Growth. Environ. Pollut. 2007, 150, 243-250.

(30) Yang, Z.; Chen, J.; Dou, R.; Gao, X.; Mao, C.; Wang, L. Assessment of the Phytotoxicity of Metal Oxide Nanoparticles on Two Crop Plants, Maize (Zea Mays L.) and Rice (Oryza Sativa L.). Int. J. Environ. Res. Public Health 2015, 12, 15100-15109.

(31) Elmer, W. H.; White, J. C. The Use of Metallic Oxide Nanoparticles to Enhance Growth of Tomatoes and Eggplants in Disease Infested Soil or Soilless Medium. Environ. Sci.: Nano 2016, 3, 1072-1079.

(32) Wang, P.; Menzies, N. W.; Lombi, E.; McKenna, B. A.; Johannessen, B.; Glover, C. J.; Kappen, P.; Kopittke, P. M. Fate of ZnO Nanoparticles in Soils and Cowpea (Vigna Unguiculata). Environ. Sci. Technol. 2013, 47, 13822-13830. Juárez-Maldonado, A.; Ortega-Ortíz, H.; Pérez-Labrada, F.; Cadenas-Pliego, G.; Benavides-Mendoza, A. Cu Nanoparticles Absorbed on Chitosan Hydrogels Positively Alter Morphological, Production, and Quality Characteristics of Tomato. J. Appl. Bot. Food Qual. 2016, 89, 183-189.

(34) Sharif, R.; Mujtaba, M.; Rahman, M. U.; Shalmani, A.; Ahmad, H.; Anwar, T.; Tianchan, D.; Wang, X. The Multifunctional Role of Chitosan in Horticultural Crops; a Review. Molecules. 2018, 23, 872. 
(35) Perez, J. J.; Francois, N. J. Chitosan-Starch Beads Prepared by Ionotropic Gelation as Potential Matrices for Controlled Release of Fertilizers. Carbohydr. Polym. 2016, 148, 134-142.

(36) Jamnongkan, T.; Kaewpirom, S. Potassium Release Kinetics and Water Retention of Controlled-Release Fertilizers Based on Chitosan Hydrogels. J. Polym. Environ. 2010, 18, 413-421.

(37) Ul-Islam, M.; Khattak, W. A.; Ullah, M. W.; Khan, S.; Park, J. K. Synthesis of Regenerated Bacterial Cellulose-Zinc Oxide Nanocomposite Films for Biomedical Applications. Cellulose 2014, 21, 433-447.

(38) Gao, X.; Spielman-Sun, E.; Rodrigues, S. M.; Casman, E. A.; Lowry, G. V. Time and Nanoparticle Concentration Affect the Extractability of $\mathrm{Cu}$ from $\mathrm{CuO}$ NP-Amended Soil. Environ. Sci. Technol. 2017, 51, 2226-2234.

(39) Wu, C. M.; Baltrusaitis, J.; Gillan, E. G.; Grassian, V. H. Sulfur Dioxide Adsorption on ZnO Nanoparticles and Nanorods. J. Phys. Chem. C 2011, 115, 10164-10172.

(40) Vasile, B. S.; Oprea, O.; Voicu, G.; Ficai, A.; Andronescu, E.; Teodorescu, A.; Holban, A. Synthesis and Characterization of a Novel Controlled Release Zinc Oxide/Gentamicin-Chitosan Composite with Potential Applications in Wounds Care. Int. J. Pharm. 2014, 463, 161-169.

(41) Tavares, D. S.; Rodrigues, S. M.; Cruz, N.; Carvalho, C.; Teixeira, T.; Carvalho, L.; Duarte, A. C.; Trindade, T.; Pereira, E.; Römkens, P. F. A. M. Soil-Pore Water Distribution of Silver and Gold Engineered Nanoparticles in Undisturbed Soils under Unsaturated Conditions. Chemosphere 2015, 136, 86-94.

(42) Hoagland, D. R.; Arnon, D. I. The Water-Culture Method for Growing Plants without Soil, 2nd Edition.; Circ. Calif. Agric. Exp. Stn, 1950.

(43) Gao, X.; Avellan, A.; Laughton, S.; Vaidya, R.; Rodrigues, S. M.; Casman, E. A.; Lowry, G. V. CuO Nanoparticle Dissolution and Toxicity to Wheat (Triticum Aestivum) in Rhizosphere Soil. Environ. Sci. Technol. 2018, 52, 2888-2897.

(44) Tso, C. P.; Zhung, C. M.; Shih, Y. H.; Tseng, Y. M.; Wu, S. C.; Doong, R. A. Stability of Metal Oxide Nanoparticles in Aqueous Solutions. Water Sci. Technol. 2010, 61,127133.

(45) Ma, J.; Sun, Z.; Wang, Z.; Zhou, X. Preparation of ZnO-Cellulose Nanocomposites by Different Cellulose Solution Systems with a Colloid Mill. Cellulose 2016, 23, 37033715.

(46) John, A.; Ko, H. U.; Kim, D. G.; Kim, J. Preparation of Cellulose-ZnO Hybrid Films by a Wet Chemical Method and Their Characterization. Cellulose 2011, 18, 675-680.

(47) Ye, S.; Zhang, D.; Liu, H.; Zhou, J. ZnO Nanocrystallites/Cellulose Hybrid Nanofibers Fabricated by Electrospinning and Solvothermal Techniques and Their Photocatalytic Activity. J. Appl. Polym. Sci. 2011, 121, 1757-1764.

(48) Corradini, E.; de Moura, M. R.; Mattoso, L. H. C. A Preliminary Study of the Incorparation of NPK Fertilizer into Chitosan Nanoparticles. Express Polym. Lett. 2010, 4, 509-515.

(49) Regiel-Futyra, A.; Kus-Lï̈kiewicz, M.; Wojtyła, S.; Stochel, G.; Macyk, W. The Quenching Effect of Chitosan Crosslinking on ZnO Nanoparticles Photocatalytic Activity. RSC Adv. 2015, 5, 80089-80097.

(50) Waalewijn-Kool, P. L.; Diez Ortiz, M.; Van Straalen, N. M.; Van Gestel, C. A. M. Sorption, Dissolution and PH Determine the Long-Term Equilibration and Toxicity of Coated and Uncoated ZnO Nanoparticles in Soil. Environ. Pollut. 2013, 178, 59-64..

(51) Donner, E.; Broos, K.; Heemsbergen, D.; Warne, M. S. J.; McLaughlin, M. J.; Hodson, M. E.; Nortcliff, S. Biological and Chemical Assessments of Zinc Ageing in Field Soils. Environ. Pollut. 2010, 158, 339-345.

(52) Romero-Freire, A.; Lofts, S.; Martín Peinado, F. J.; van Gestel, C. A. M. Effects of 
Aging and Soil Properties on Zinc Oxide Nanoparticle Availability and Its Ecotoxicological Effects to the Earthworm Eisenia Andrei. Environ. Toxicol. Chem. 2017, 36, 137-146.

(53) Ma, W. C.; Bonten, L. T. C. Bioavailability Pathways Underlying Zinc-Induced Avoidance Behavior and Reproduction Toxicity in Lumbricus Rubellus Earthworms. Ecotoxicol. Environ. Saf. 2011, 74, 1721-1726.

(54) Kanakaraju, D.; Ravichandar, S.; Lim, Y. C. Combined Effects of Adsorption and Photocatalysis by Hybrid TiO2/ZnO-Calcium Alginate Beads for the Removal of Copper. J. Environ. Sci. (China) 2017, 55, 214-223.

(55) Marschner, H. Zinc Uptake from Soils. In Zinc in Soils and Plants; Robson A.D., Ed.; Springer, Dordrecht.1993

(56) Hortin, J. M.; Anderson, A. J.; Britt, D. W.; Jacobson, A. R.; McLean, J. E. SoilDerived Fulvic Acid and Root Exudates, Modified by Soil Bacteria, Alter $\mathrm{CuO}$ Nanoparticle-Induced Root Stunting of Wheat: Via Cu Complexation. Environ. Sci.: Nano 2019, 6, 3638-3652.

(57) Gao, X.; Rodrigues, S. M.; Spielman-Sun, E.; Lopes, S. ; Rodrigues, S.; Zhang, Y.; Avellan, A.; MBO Duarte, R.; Duarte, A.; Casman, E. A.; et al. Effect of Soil Organic Matter, Soil PH, and Moisture Content on Solubility and Dissolution Rate of CuO NPs in Soil. Environ. Sci. Technol. 2019, 53, 4959-4967.

\section{For Table of Contents Only}

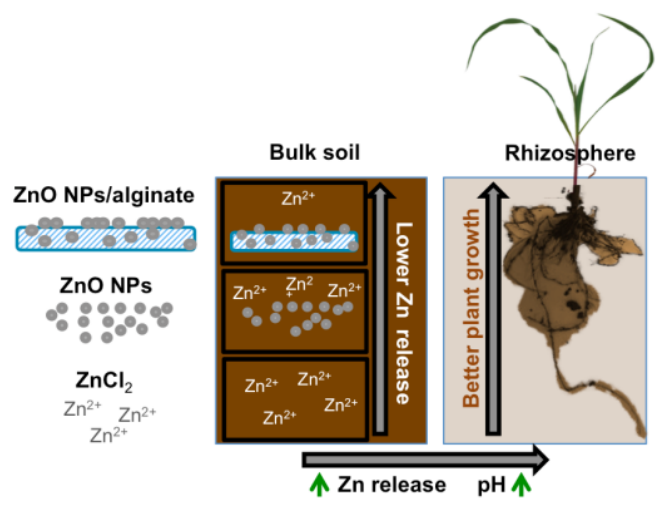

